\title{
Energy integration study on a hybrid electric vehicle energy system, using process integration techniques
}

\author{
Zlatina Dimitrova $^{a, b}$, François Maréchal $^{b}$ \\ ${ }^{a}$ PSA Peugeot Citroën, Vélizy, France, zlatina.dimitrova@mpsa.com \\ ${ }^{b}$ Ecole Polytechnique Fédérale de Lausanne, Lausanne, Switzerland, zlatina.dimitrova@epfl.ch \\ ${ }^{b}$ Ecole Polytechnique Fédérale de Lausanne, Lausanne, Switzerland, francois.machechal@epfl.ch
}

\begin{abstract}
:
The needs of efficiency improvement of the vehicle energy systems require to find innovative solutions during the design process, integrating all vehicle services and energy requirement on a vehicle system level.

In this article the boundary of the energy system are extended to the powertrain and the cabin and the requirements for mobility and comfort are integrated.

The energy balance of the internal combustion engine is done and discussed, according to its operating points. The energy requirement for comfort in the cabin is also determined, according to the seasonal requirement for heating or cooling. In this article an energy integration methodology, using process integration techniques is discussed and applied on the extended vehicle energy system. The minimal energy requirement is determined for different mobility and comfort situations. The energy recovery potential of an organic Rankine cycle, with sensitivity of different working fluids, is assessed.

The energy integration methodology is applied on a hybrid electric vehicle energy system, and is studied for adapted dynamic profile, represented by characteristic clustered operating points.

Multi-objective optimization is applied to define the optimal design of a hybrid electric powertrain and the optimal ICE size, from efficiency and cost point of view.
\end{abstract}

\section{Key words:}

Energy vehicle balance, Energy integration, Internal Combustion Engine (ICE) efficiency, Hybrid electric vehicle, Organic Rankine Cycle (ORC), Process integration techniques

\section{Nomenclature}

$\begin{array}{ll}\text { NEDC } & \text { New European Drive Cycle } \\ \text { SI } & \text { engine Spark ignition engine } \\ \text { ICE } & \text { Internal combustion engine } \\ \text { EM } & \text { Electric machine } \\ \text { Car shell } & \text { equipped car without the powertrain } \\ \text { SC } & \text { Super capacitor } \\ H V B T & \text { High voltage battery } \\ q_{b a t} & \text { Battery capacity } \\ \text { LHV } & \text { Low Heating Value in }[\mathrm{kJ} / \mathrm{kg}]\end{array}$




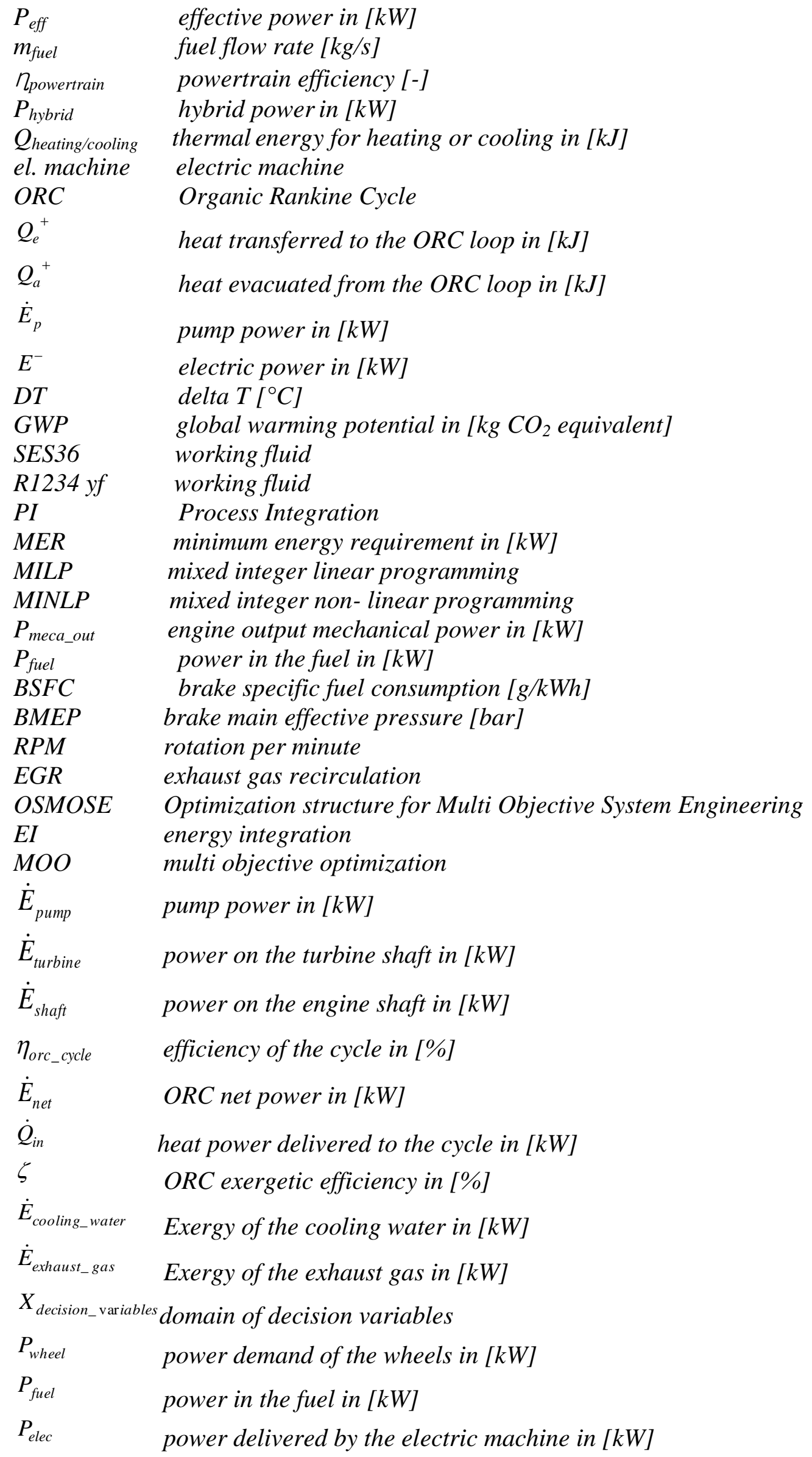




$\begin{array}{ll}P_{I C E} & \text { power of the ICE in } k W[\mathrm{~kW}] \\ P_{S C} & \text { power of super capacitors in }[\mathrm{kW}] \\ C_{\text {vehicle }} & \text { vehicle cost in }[€] \\ C_{\text {car }{ }_{-} \text {shell }} & \text { cost of the car shell in }[€] \\ C_{I C E} & \text { cost of the ICE in }[€] \\ C_{E M} & \text { cost of the EM in }[€] \\ C_{H V B T} & \text { cost of the high voltage battery in }[€] \\ C_{S C} & \text { super capacitor cost in }[€]\end{array}$

\section{Introduction}

The target of the present work is to illustrate the methodological transfer of the energy integration from the process engineering to the vehicle energy systems design and so to assess the theoretical potential for efficiency improvement and fuel consumption reduction through heat recovery, using working cycles as utilities.

The novelty and the purpose of this paper are to apply the single energy optimization and process integration on an autonomous and dynamic energy system - the vehicle. The energy system boundaries are extended. The vehicle powertrain and the cabin are defined as unitary processes, with heat exchange that has to be integrated, in function of the ambient temperature. In order to do so, an energy integration model based on mixed integer linear programming (MILP) has been developed. A hybrid electric vehicle dynamic model gives the thermal and the mechanical flows of the vehicle. The engine thermal model is calibrated with a real engine map measurement. This study zooms especially on the energy integration structure. This structure is used as a slave structure linked by the state variables with the dynamic and the thermal models (Figure 4). The problem statement and the energy recovery potential of the ORC are developed in the part "Results".

\subsection{Mobility and energy balance:}

Passenger cars are evaluated in standardized test cycles. In Europe, the New European Driving Cycle (NEDC) is used, in which only the energy needed for the propulsion is considered. Figure 1 displays a real measured efficiency map for a thermal engine. 


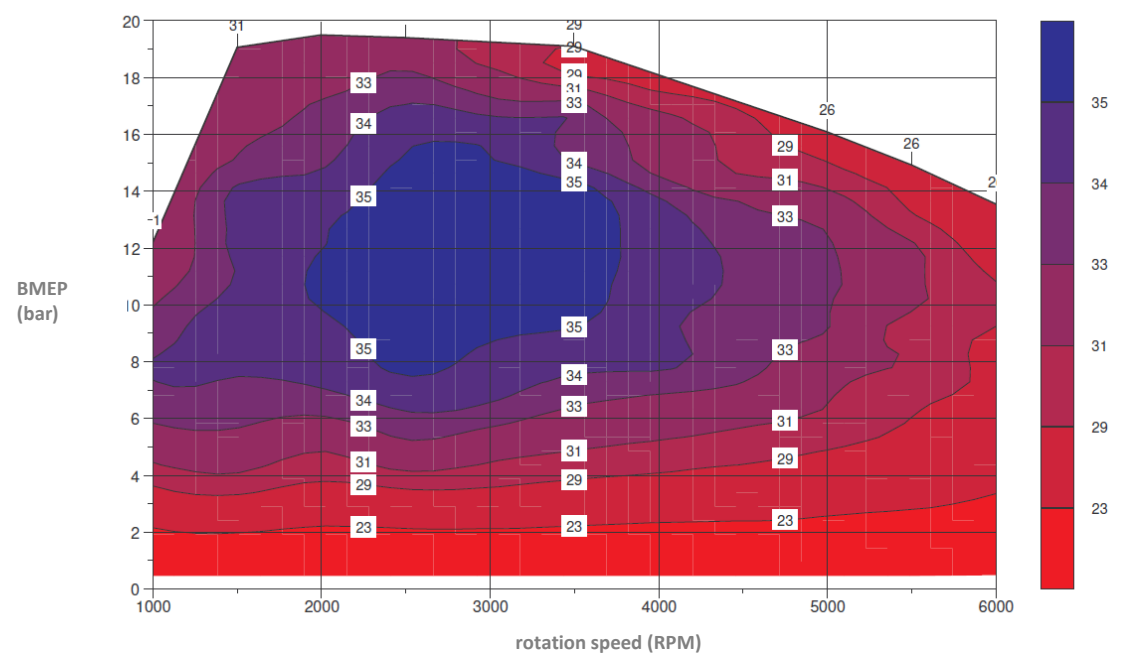

Figure 0-1 : Efficiency map of turbocharged homogenous combustion gasoline engine

The characteristics and the efficiency order of magnitude for internal combustion engines are reviewed in [1].

The Tank-to-Wheel energy efficiency considers the propulsion energy needs of the vehicle.

$\eta_{\text {powertrain }}=\frac{P_{\text {eff }}}{m_{f u e l}{ }^{* L H V}}=\frac{P_{\text {eff }}}{P_{\text {input stored in the tanks }}}[-]$

For the Tank-to-Wheel balance, depending on the powertrain, and for the NEDC, the average efficiency is between:

- $20 \%$ for thermal powertrain

- $30 \%-35 \%$ for hybrid electric.

The energy losses are then between $80 \%$ and $65 \%$ [2].

The energy services delivered in a vehicle are:

- Mobility

- Comfort

- Safety

Therefore, it is needed to perform energy balance and energy analysis on the extended vehicle system, including the fuel consumption and the other vehicle services.

In this study, the boundaries of the energy system are extended including the comfort service. The application is done on a hybrid electric vehicle with kinetic energy recovery. Equation 2 summarizes the new system definition.

$\eta_{\text {vehicle }}=\frac{P_{\text {eff }}+P_{\text {elec }}+P_{\text {hybrid }}+Q_{\text {cooling } / \text { heating }}}{P_{\text {input energy stored in the energy tanks }}}[-]$

In an internal combustion engine, the chemical energy is converted to heat and then to mechanical energy.

The heat dissipated in the cooling liquids and the exhaust gases of the engine can be used to heat the cabin, or to be converted in electricity or cooling.

For that an energy integration methodology is applied on a dynamic energy system. The energy integration methodology is applied on a simultaneous way for the mobility and the comfort vehicle service. This represents an innovative approach in the vehicle design. 
According to the ambient temperature and the requirement for comfort (cooling or heating), the ICE heat losses can be used to heat the cabin or to be converted to electricity or cold air, using utilities cycles to close the energy balance.

Several concepts for the engine heat losses recovery exist in the literature. Liu et al. proposed comparison and analysis of engine exhaust gas energy recovery potential through various bottom cycles in [3]. The study included direct recovery means through exhaust gas expansion, such as secondary expansion, and indirect recovery means through heat transfer, such as Rankine steam cycle, Brayton air cycle, etc. The conclusion is that the Rankine cycle presents the best heat recovery potential and the largest application range.

The rankine cycle studies on engine heat recovery proliferate. Bari and Hossein stated in [4] that the exhaust heat from diesel engines can be an important heat source to provide additional power using a separate Rankine Cycle. They conduct experiments and found that $16 \%$ of additional net power output can be found on a diesel engine. An additional idea was to use also the low and the medium temperature heat domain for the recovery and so the organic fluids are introduced as working fluids for the rankine cycles. For example, Sprouse and Depik dressed in [5] the review of ORC for ICE exhaust heat recovery. The introduction of organic fluids proposes major choice of working fluids impacting the performance indicators of the rankine cycle. Jung et al. studied in [6] the selection of appropriate fluids for the rankine cycle used for exhaust gases heat recovery in heavy- duty series hybrid vehicles. $\mathrm{R} 245$ is proposed as working fluid.

The recovery can be also focused on the water circuit heat. Borretti introduced in [7] the idea for recovery of the coolant and exhaust gases heat by the ORC in a hybrid passenger car with natural aspirated gasoline engine. He assessed the major recovery potential to $8.2 \%$ for the combined water and exhaust gases effect. Quoilin et al. applied a thermo-economic optimization of an ORC for small scale industrial applications in [8]. They stated that the optimum of each performance indicator- net power, thermal and exergatic efficiency of the ORC bellows to different operating points. They also correlate the cost on the ORC components size.

The potential of the ORC is also related to the loop architecture and the components design. Various architectures and turbo machines design are studied. Wang and al. studied for example in [9] a potential of a dual ORC loop for a diesel engine. Zhu et al studied in [10] the impact of the expansion ratio of the expander on the ORC performances.

Dolz et al. [11] described Rankine cycle for diesel heavy duty engine with R245a and water as working fluid. The energy recovery and the power output of the engine are improved with 89\%. The replacement of the working fluid to Fluor ether mixture increases the energy recovery potential to $10-15 \%$.

Capata et al. studied in [12] a small-scale ORC energy recovery system for vehicular application. In this paper the heat was recovered from the exhaust gases of a typical diesel engine $(1400 \mathrm{cc})$ or a small gas turbine set $(15-30 \mathrm{~kW})$. The recovery system can produce extra power to sustain the conditioning system or other auxiliaries.

Peris et al. [13] studied suitable cycles for ICE cooling water waste recovery. Double regenerative cycle, using SES36 is highlighted as most efficient configuration, with improvement of the electrical efficiency of up to $5.3 \%$.

The improvement of performances of the air conditioning system using refrigerants R134a and R1234yf was studied in [14]. Bombarda et al. in [15] studied the ORC in comparison of Kalina cycle for diesel engines.

It is evident that the working fluid choice for vehicle applications is restricted to regulated fluids authorized for automotive applications.

The novelty of this study is to illustrate the methodological transfer of the energy integration from the process engineering to the vehicle energy systems design. An organic Rankine cycle 
is used as utility and its theoretical potential for efficiency improvement of the vehicle powertrain is assessed. This methodology allows integrating the mobility and the comfort services of the vehicle.

\section{Methodology - Process and multi-objective optimization}

\subsection{Energy Integration model}

The process optimization proposes a structured methodology to identify, characterize and quantify the waste heat of a system. The process integration (PI) methodology dates back to the 1970s and the first developments are in the heat integration [16]. The PI is deployed in the oil, chemical and energy industry [16]. Linnhoff in [17] illustrated the pinch method for heat exchangers design and heat integration. Some developments in the PI applied to the chemical engineering research are summarized in [18]. Dimian et al. summarized the basics of the Pinch point analysis in the recent publication [19].

In this article the efficiency improvement of the hybrid electric vehicle powertrain through PI is researched.

The energy integration methodology is based on the heat integration, which targets the maximum heat recovery in the energy system. The approach consists in mapping all hot and cold streams in the system and displays the heat composite curve. The methodology gives the advantage to provide a global picture of the heat exchanges in the system. It also provides the MER - minimum energy requirement. MER is the minimum amount to be introduced or extracted from the system by means of cold or hot utilities. As a result, the utilities are selected and sized.

Process integration techniques and energy analysis are used to measure the useful potential of the waste heat [20].

\subsubsection{Working cycles and heat recovery systems as utilities}

According to the temperature level of the heat sources, different technologies for heat to electricity conversion can suit.

For high temperature of the exhaust gases or high air temperature, the conventional Rankine cycle suits very well.

For low temperature heat source (around $120^{\circ} \mathrm{C}$ ), Kalina cycle, with mixture of WaterAmmonia for working fluid, is an efficient technology. For ever lower powers and for different temperature levels of the heat source, the organic rankine cycle (ORC) presents an interest. The Figure 2 illustrates the ORC steps:

- $1 \rightarrow 2$ the working fluid is compressed from the condensation pressure level to the work pressure level

- $\quad 2 \rightarrow 3$ in the heater, the heat is coming from the hot source, the fluid is evaporated; When it is needed, it is possible to super heat till the maximal process temperature.

- $3 \rightarrow 4$ the working fluid expends in the expender, which is generally powering a generator for electricity production. After that, the work fluid transfers the heat to the cold source and the liquid is liquefied in the condenser. 


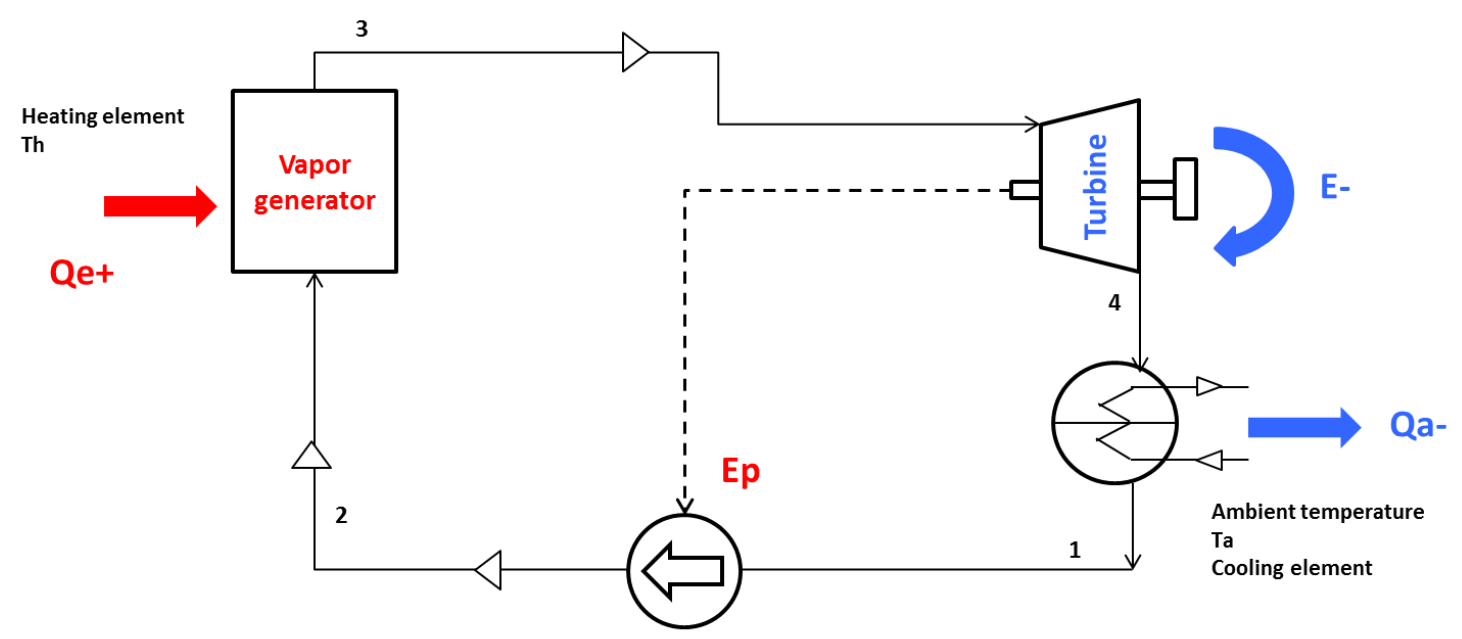

Pump for fluid

Figure 2: ORC installation [21]

The working fluid choice is an improvement aspect for the ORC efficiency. The working fluids are chosen considering thermos-physical properties, safety and environmental impact.

\subsection{Computation model and OSMOSE superstructure}

For system problems optimization, numerical approaches are used. In this study, the energy integration is performed with the OSMOSE tool.

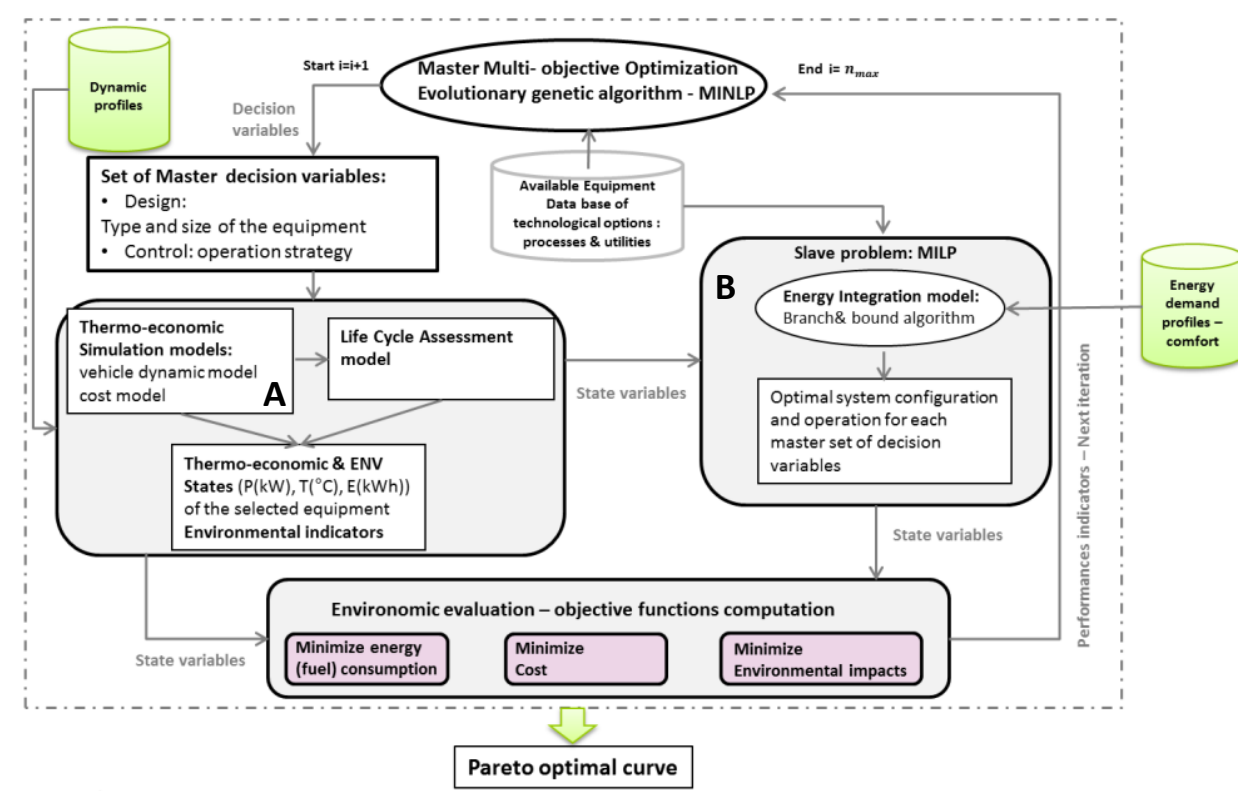

Figure 3: Energy integration structure and OSMOSE superstructure

The general computational framework of OSMOSE has already been described in Gerber (2011) and adapted for vehicle applications in [22] and [23]. The optimizer in OSMOSE is based on a genetic algorithm. This optimization technique is multi- modal and gives local optimums. The developed model is a mixed integer nonlinear problem (MINLP). It is solved by decomposition method using a master slave algorithm in which decision variables can be in master or slave sets [24]. 
In this article, the flow sheeting (Matlab- Simulink ${ }^{\circledR}$ ) vehicle tool is mainly used for simulation. It is represented as module (A) (Figure 4).

The energy integration (EI) approach is a slave optimization problem represented by the module (B) (Figure 3). The energy integration defines the potential of heat recovery and deduces the choice and the sizing of the adapted utilities.

The heat cascade and the energy balance are defined as the main constraints in the slave optimization (MILP).

In this article, the superstructure OSMOSE is used in mode "one run" simulation - between the thermodynamic model (A) and the energy integration model (B). The simulation problem is defined by giving the vehicle parameters (mass, propulsion type and size) and the driving profile - NEDC. The out coming results are the fuel consumption of the vehicle, the definition of the typical operating points for the thermal engine for NEDC and the engine heat balance for the typical operating points.

The article presents an example of multi-objective master optimization which helps to optimize the size of the internal combustion engine, included in the vehicle powertrain.

The energy integration is the second stage of the approach and it is a slave optimization based on mixed integer linear programming. The energy integration defines the potential of heat recovery and deduces the choice and the sizing of the adapted utilities. In the energy integration problem the engine and the vehicle cabin are defined as processes exchanging heat between them. The utility system pertinent for energy recovery - the organic Rankine cycle is defined in the energy integration module. In the EI the level of temperatures (condensation and evaporation) of the ORC are optimized to obtain the maximal net power output. The optimization is done for each operating point and each working fluid and comfort demand. The outcomes of this optimization are the ORC loop sizing (working fluid flow, sizes of the turbo machines and exchanged heat in the evaporation and the condensation) the efficiency and the net power output.

This article states the basics of the energy integration methodology, illustrating a one run simulation problem on standardized driving cycle - new European driving cycle.

The master optimization (Figure 3), where belongs the evolutionary algorithm is illustrated in the second part of the article.

\section{Results: Process integration applied on hybrid electric vehicle heat balance}

\subsection{Problem definition}

\subsubsection{Engine energy balance}

The energy balance of an internal combustion engine (Figure 4) shows that a big amount of energy $\sim 30 \%$ (average on NEDC) is dissipated as heat in the exhaust gases, and around 40\% as heat in the liquids (water and oil). In an engine operating field, these proportions change in function of the load and the rotation speed at the operation point.

With increased rotation speed, the mechanical power output is also increasing - for the displayed diesel engine in Figure 4, the peak power is $116 \mathrm{~kW}$ at 4,000 rpm.

The ratio between the fuel power and the mechanical output power corresponds to the engine efficiency.

$$
\eta=\frac{\text { Pmec_out }}{\text { Pfuel }}=\frac{1}{B S F C * L H V} \quad[\%]
$$

The difference between the fuel power and the mecanical power output is defining the engine losses (Eq. 5). 


$$
P_{\text {losses }}=P_{\text {fuel }}-P_{\text {mec_out }}
$$
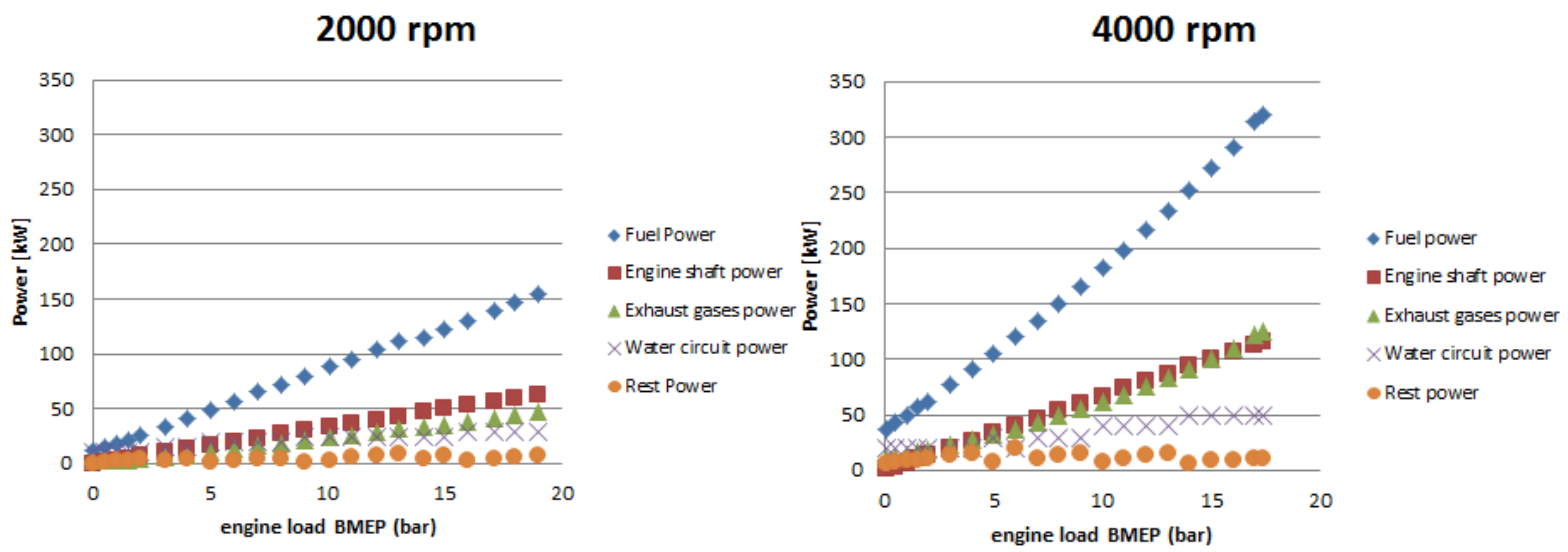

Figure 4: Engine energy balance for rotation speed and load variation-diesel engine $2 l$, EURO 4, measurements map [1]

With increased load, the energy efficiency increases and the losses are mainly due to the heat dissipation in the exhaust gases and the engine cooling fluids. At low speeds and low loads, the energy dissipation in the fluids is bigger than in the exhaust gases. With increased rotation speed and loads, the tendency is inversed and the exhaust gases losses are dominant. For the peak power point, it is equal to the mechanical power output $\sim 116 \mathrm{~kW}$.

The water and oil temperatures are regulated in the heat exchangers. The regulation temperature is $90^{\circ} \mathrm{C}$ for the water and $100^{\circ} \mathrm{C}$ for the oil. Based on the experimental sets of data, presented in Figure 5, a 1D thermal model of the Diesel engine is calibrated. A full decomposition of the energy losses is performed - Figure 5 displays the energy balance for the engine operating point 2,800 rpm 8 bar BMEP.

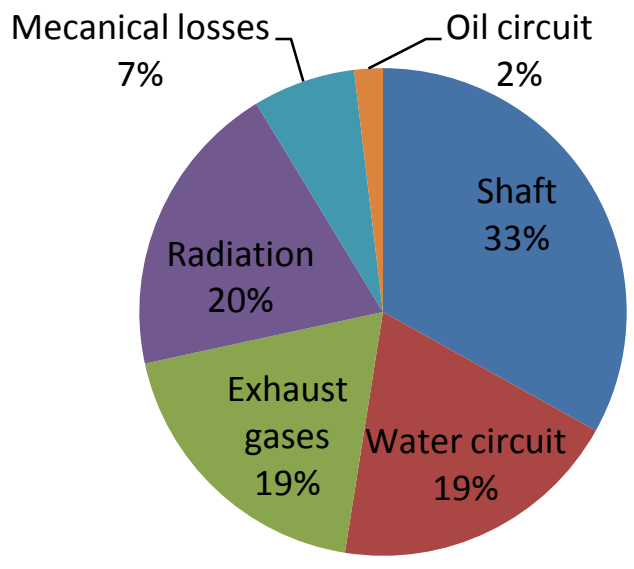

Figure 5: Engine energy balance on 2,800 rpm 8 bar BMEP

The conclusion of the energy balance is that the heat losses are dominant. The vehicle system has an excess of hot flows - exhaust gases, heat dissipation in water and oil, radiation (Figure $6)$.

The average values calculated on NEDC for hybrid electric vehicles with 21 diesel engine are respectively $-23.5 \%$ energy losses in the exhaust gases and $47 \%$ losses in the fluids. The 
recovery potential of the heat seems important in comparison of the kinetic energy recovery in the case of an electric hybridization. For example, the energy recovery in the deceleration phases for hybrid electric vehicle is $10 \%$.

In the case of a hybrid electric vehicle, one decides to extend the system boundary from the powertrain to the vehicle including the cabin requirements for comfort - heating and cooling. This new energy system needs to be integrated. The novelty of the article is to propose to use the pinch point methodology on a vehicle system. To apply the energy integration methodology, we need to characterize the system on its typical operating points.

Passenger cars are evaluated in standardized test cycles. In Europe, NEDC is used, and only the energy needed for the propulsion is considered. So it is defined the Tank-to-Wheel efficiency. This cycle is constituted from two parts: UDC - Urban Driving Cycle and EUDC - Extra Urban Driving Cycle (Figure B.1).

The high number of points of the dynamic profile is increasing the optimization calculation time. The use of typical periods provides an efficient alternative for reducing the numbers of variables. The dynamic drive cycle can be represented as limited sets of periods.

To apply the energy integration methodology, one needs to characterize the system on its typical operating points. The goal is to minimize and to find the optimal number of clusters. Five typical points are determined. They are corresponding to the use of the thermal engine in a middle class hybrid electric vehicle on the NEDC (Table 1). The five points are the main clusters of the thermal engine power distribution on the NEDC. They are determined by using a k-means algorithm for clustering the ICE delivered power profile on NEDC (Figure B.2). These points are representative for the comfort system design, in the case of the NEDC and hybrid electric powertrain. More information about the k-means algorithm is given in Appendix 2.

The goal is to calculate the minimum energy requirement for typical operating points in the engine operating field, as well for typical summer and winter days. The MER (minimum energy requirement) is the minimum amount of energy that must be supplied externally through utilities. The data for the MER calculation are summarized in Table 1 . The values are coming from the diesel engine model calibrated with the experimental data from the Figure 3.

Table 1: Engine operating points

\begin{tabular}{cccccc}
\hline & Point 1 & Point 2 & Point 3 & Point 4 & Point 5 \\
\hline Power at shaft [kW] & 19 & 11 & 7 & 3 & 0.8 \\
RPM & 2,800 & 2,100 & 1,800 & 1,500 & 1,000 \\
Torque $(\mathrm{Nm})$ & 60 & 50 & 37 & 19 & 8 \\
BMEP & 4 & 3 & 2 & 1.17 & 0.45 \\
Air flow rate $[\mathrm{kg} / \mathrm{h}]$ & 272.82 & 104.31 & 70.85 & 41.97 & 27.7 \\
Fuel flow rate $[\mathrm{kg} / \mathrm{h}]$ & 5.99 & 3.3 & 2.38 & 1.33 & 0.64 \\
Water flow rate $[\mathrm{l} / \mathrm{min}]$ & 112 & 72.6 & 73.5 & 58.8 & 39 \\
Oil flow rate [l/min] & 25.5 & 21 & 19 & 16 & 9 \\
EGR [\%] & 40 & 40 & 54 & 38 & 0 \\
\hline
\end{tabular}

\subsubsection{Minimum energy requirement MER - vehicle energy integration}

Hot and cold streams are defined in the Energy Integration structure of OSMOSE (Figure 3) and the energy integration model is launched for each operating point. The composites curves of the processes are calculated. 


\section{Hot and cold streams}

The energy integration model is composed of the streams with the direct needs from the engine and the cabin, differentiated for different ambient temperatures $-0^{\circ} \mathrm{C}$ for winter day (Table 2) and $30^{\circ} \mathrm{C}$ for hot summer day (Table 3). The heat capacities of the streams are in Table A.1.

Table 2: Winter case $-0^{\circ} \mathrm{C}$ ambient Temperature, hot and cold streams

\begin{tabular}{ccc}
\hline Stream & Inlet Temperature $\left[{ }^{\circ} \mathbf{C}\right]$ & Outlet Temperature $\left[{ }^{\circ} \mathbf{C}\right]$ \\
\hline Cabin air & 0 & 20 \\
Fuel Heating & 30 & 41 \\
\hline Intercooler ${ }^{2}$ & $\sim$ (engine map value) & 40 \\
Exhaust cooling & $\sim$ (engine map value) & 0 \\
Cooling water & 90 & 88 \\
Engine oil & 100 & 98 \\
EGR & $\sim$ (engine map value) & 40 \\
\hline
\end{tabular}

Table 3: Summer case- $30^{\circ} \mathrm{C}$ ambient temperature, hot and cold streams

\begin{tabular}{lcc}
\hline Stream & Inlet Temperature $\left[{ }^{\circ} \mathbf{C}\right]$ & Outlet Temperature $\left[{ }^{\circ} \mathbf{C}\right]$ \\
\hline Fuel Heating & 30 & 41 \\
\hline Cabin air & 30 & 20 \\
Intercooler & $\sim$ (engine map value) & 40 \\
Exhaust cooling & $\sim$ (engine map value) & 0 \\
Cooling water & 90 & 88 \\
Engine oil & 100 & 98 \\
EGR & $\sim$ (engine map value) & 40 \\
\hline
\end{tabular}

Finally for the various streams types, the general $\Delta T_{\min } / 2$ values from Table 4 are chosen for energy and utilities integration. The $\Delta T_{\min }$ introduces the minimum temperature difference between hot and cold streams for heat exchangers ([25] and [26]).

\begin{tabular}{cr}
\multicolumn{2}{c}{ Table 4: $\Delta T_{\min } / 2$ values } \\
\hline Stream type & $\Delta T_{\min } / 2\left[{ }^{\circ} \mathrm{C}\right]$ \\
\hline Gas & 15 \\
Liquid & 5 \\
Evaporating & 2 \\
Condensing & 3 \\
\hline
\end{tabular}

The MER is computed for the winter and summer case. The next figures (Figure 6 and Figure 7) display the composite curves for point 1 and point 5 - the highest and the lowest charged points. 


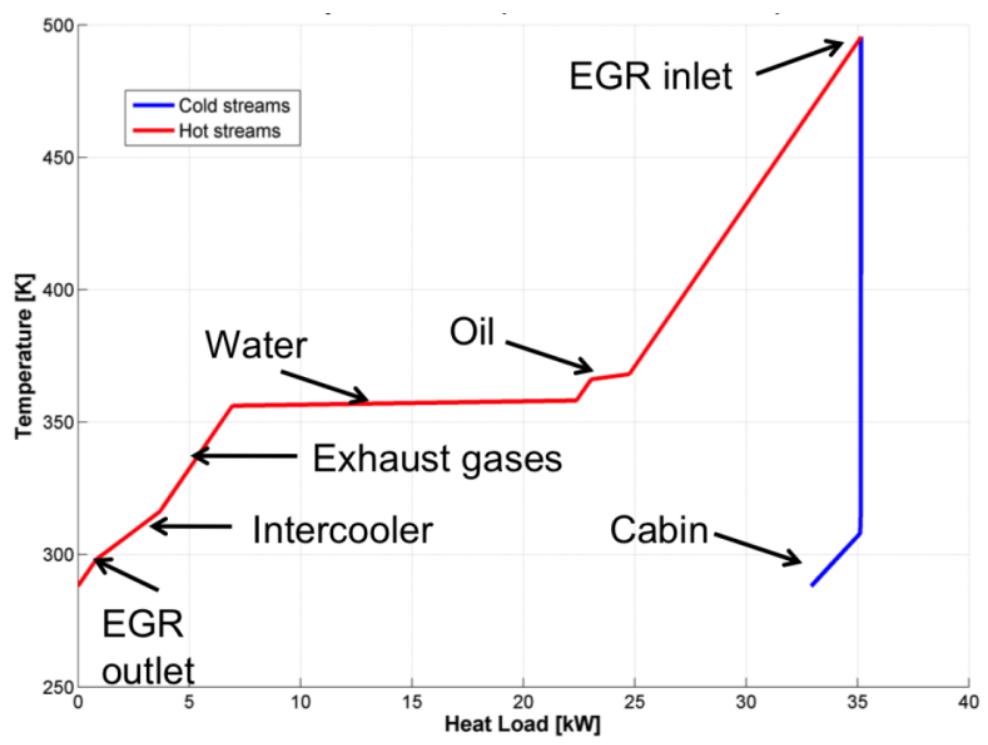

a)

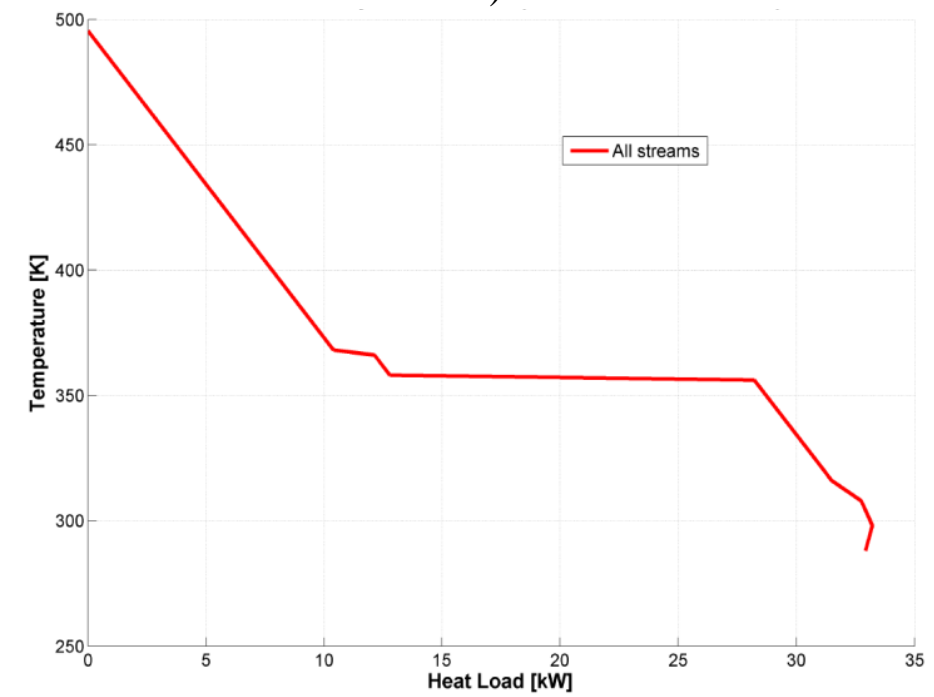

b)

Figure 6: a) Composite Curves and b) Grand Composite Curve for operating point 1, in winter 


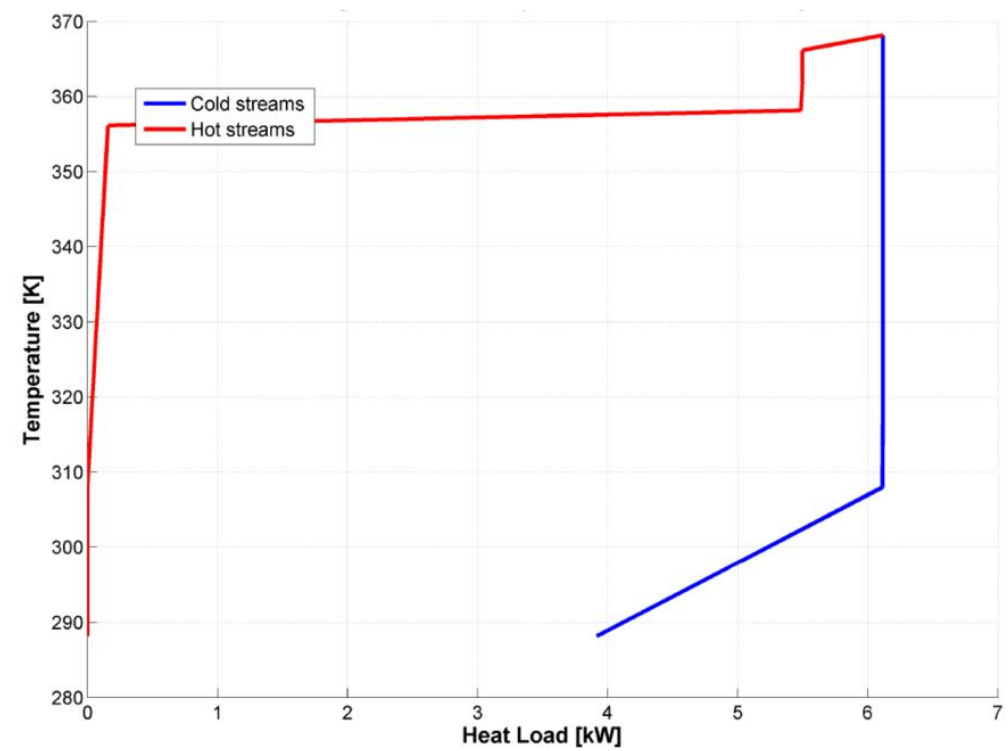

a)

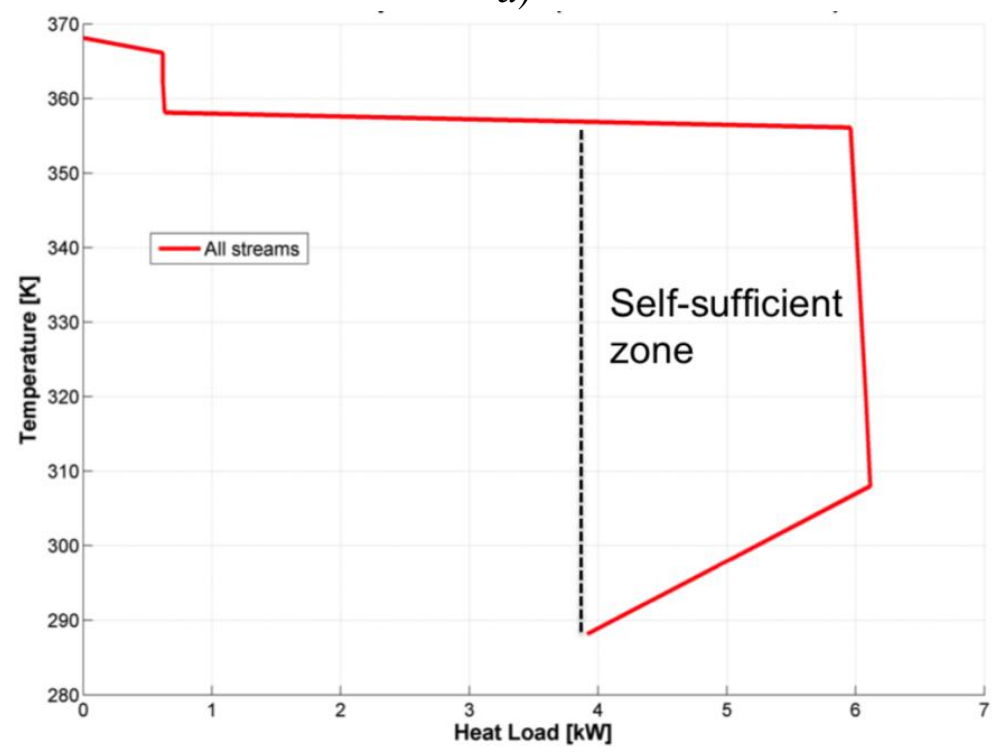

b)

\section{Figure 7: a) Composite Curves and b) Grand Composite Curve for operating point 5, in winter}

Globally, the system requires only cooling, no hot utility is needed. The pinch point is located on the top.

The results reflect the vehicle power distribution on the drive cycle. The operating points for NEDC are low charged. In the energy balance, the water stream has high heat load compared to the others streams. The oil stream load is small, around $3-4 \mathrm{~kW}$. This is due to the low load operating points.

The cabin load is also small compared to the other streams. With the decreasing load of the engine in the winter case, the cabin load represents larger self-sufficient zone - no utilities are required. This principle of heat recovery from the engine to heat the cabin is used in today's vehicles. One can see the pertinence in Figure 8 . The heating demand is recovered by $2 \mathrm{~kW}$ (point 5) from the heat load of the water circuit.

For the summer case, the system also requires only cooling. The MER values for the winter and the summer cases are given in the Table 5: 
Table 5: MER for winter and summer cases

\begin{tabular}{lccccc}
\hline & Point 1 & Point 2 & Point 3 & Point 4 & Point 5 \\
\hline MER for winter $\mathbf{0}^{\circ} \mathbf{C}$ & & & & & \\
MER cold $[\mathrm{kW}]$ & 32.92 & 18.83 & 13.38 & 8.28 & 3.91 \\
MER hot [kW] & 0 & 0 & 0 & 0 & 0 \\
MER for summer $\mathbf{3 0} 0^{\circ} \mathrm{C}$ & & & & & \\
MER cold $[\mathrm{kW}]$ & 35.42 & 21.87 & 16.49 & 11.42 & 7.10 \\
MER hot $[\mathrm{kW}]$ & 0 & 0 & 0 & 0 & 0 \\
\hline
\end{tabular}

The main difference in MER values for winter and summer is due to the cabin requirement change from cold to hot stream. The fuel stream heating has a very limited effect. The fuel temperature is regulated because of the combustion needs. So this heat exchange can be neglected.

\section{Utility Integration with ORC}

The Grand Composite Curves show that the integrated system requires only cold utilities in order to cool down all hot streams. In this paper, the integration of ORC to transform the heat into mechanical power is discussed. The ORC is implemented in the EI module of OSMOSE as technological option for utilities. The energy integration calculation allows to size the ORC installation and to give a first idea about the recovery potential. The results are summarized in Table 7. A basic Grand Composite Curve from [19] is presented in Appendix A (Figure A. 2). As discussed in the literature review, the choice of working fluid is important for the cycle efficiency and the GWP 100 years is an important criteria for its choice. In the current car regulation for refrigerants, R134a will be replaced by R1234yf. The car industry has interest in $\mathrm{CO}_{2}$ and ammonia. $\mathrm{CO}_{2}$ is interesting fluid because of low critical temperature but requires at the present stage big $R \& D$ investment. The ammonia is interesting because of its presence on the vehicle board, applied today in the NOx- after treatment systems for diesel engines.

Table 6: Working fluids

\begin{tabular}{lllrrc}
\hline & R245 & R134a & R1234yf & $\mathbf{C O}_{\mathbf{2}}$ & Ammonia \\
\hline GWP 100 & 1030 & 1430 & 4 & 1 & 0 \\
Critical temperature $\left[{ }^{\circ} \mathrm{C}\right]$ & 154 & 101 & 95 & 31 & 132 \\
\hline
\end{tabular}

For the first study, R1234yf and ammonia are selected, because of low GWP impact and low critical temperature.

Figures 8 and 9 display the integrated Composite Curves for the operating points 1 and 5 .

The study case in winter is chosen for presentation.

The integrated composite curve is obtained after integration of the composite curve and the minimum energy requirement for an external utility - the ORC. The energy recovery balance is than defined. The energy system composed from the thermal engine and the cabin is in excess of heat and to close the energy balance a "cold" utility is needed - this is the ORC. Figures 8 and 9 represent the variation of the Carnot factor as a function of the exchanged heat between the working fluid of the ORC mainly with the water circuit and the exhaust gases. The exergy losses are represented by the area between the composite curve and the utility curve. The optimization of the ORC loop consists in the minimization of this area. More detailed introduction in the composite curves is available in [16], [20] and [27]. 
Carnot factor $\Theta=1-\frac{\text { Tambient }}{T i}$

- $\mathrm{T}_{\text {ambient }}=0^{\circ} \mathrm{C}$ for the winter case

- $\mathrm{T}_{\mathrm{i}}$ is the temperature of the hot sources - the engine water circuit temperature, the engine exhaust gases temperature. (Table 2).

- The temperature of the water circuit in the ICE is regulated for engine efficiency needs.

The curves for ammonia on the point 1 are plotted in the 2 axes $\left(\mathrm{T}^{\circ} \mathrm{C}\right.$ and Carnot Factor) (Figure A.3).

The pinch point is located in the top of the GCC and the cold utility the ORC is below the pinch point, this means that the engine release heat to the ORC.

The slopes of the superheating and the preheating are the same. The direction of the slopes of the streams preheating, superheating doesn't change (Figure 8 and 9).

The following assumptions are fixed for the evaporation and the condensation:

- The condensation temperature is determined by the ambient temperature. In the plotted diagrams for the winter case the value is almost 0 . The delta $T_{\min } / 2$ for condensing is taken from Table 4 and the condensing stream is considered with $3^{\circ} \mathrm{C}$.

- The ambient air stream is needed to close the area between the cabin stream (at negative temperature in the winter) and the condensation temperature level (the ambient temperature Figure 8a).

- The evaporation temperature is determined by the engine cooling water outlet temperature. The delta Tmin/ 2 for evaporation is taken from Table 4 and the evaporating stream is considered with a value of $2^{\circ} \mathrm{C}$. For this reason the stream is almost flat and parallel to the water stream (Figure 8a).

- Ambient air and post-turbine cooling are artificial numerical streams to reach the condensation level temperature.

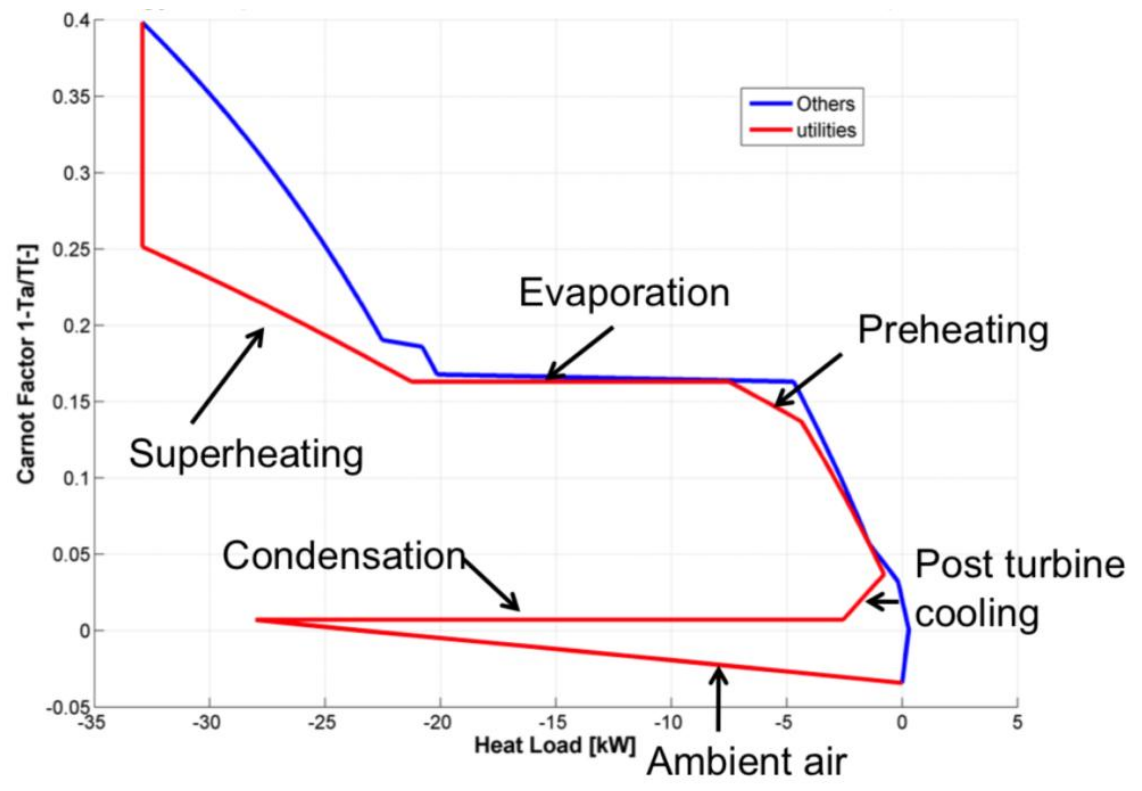




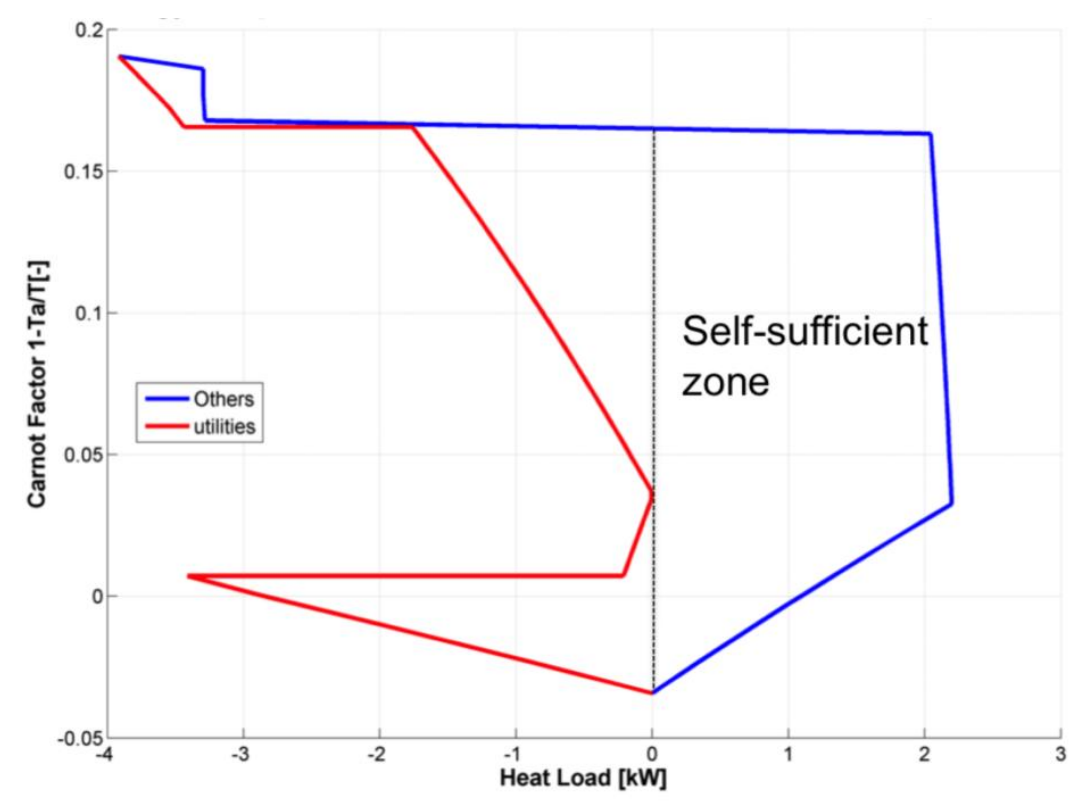

b)

Figure 8: ORC integration with R1234yf, a) point 1 and b) point 5

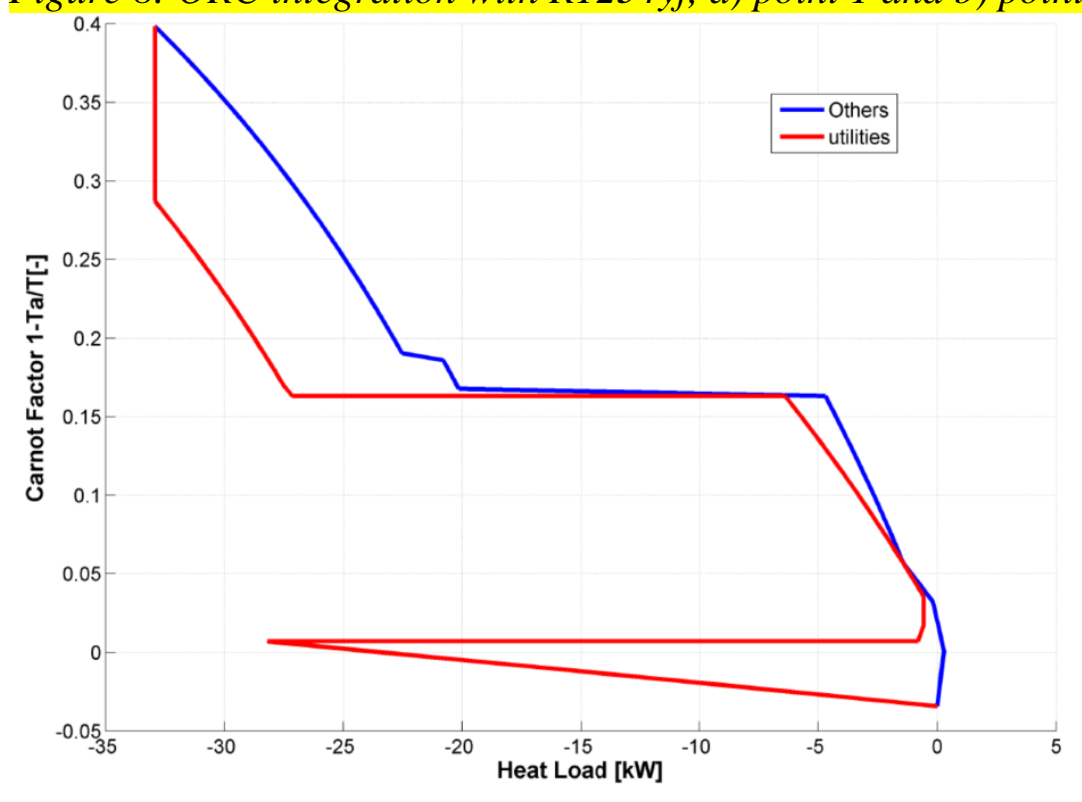

a) 


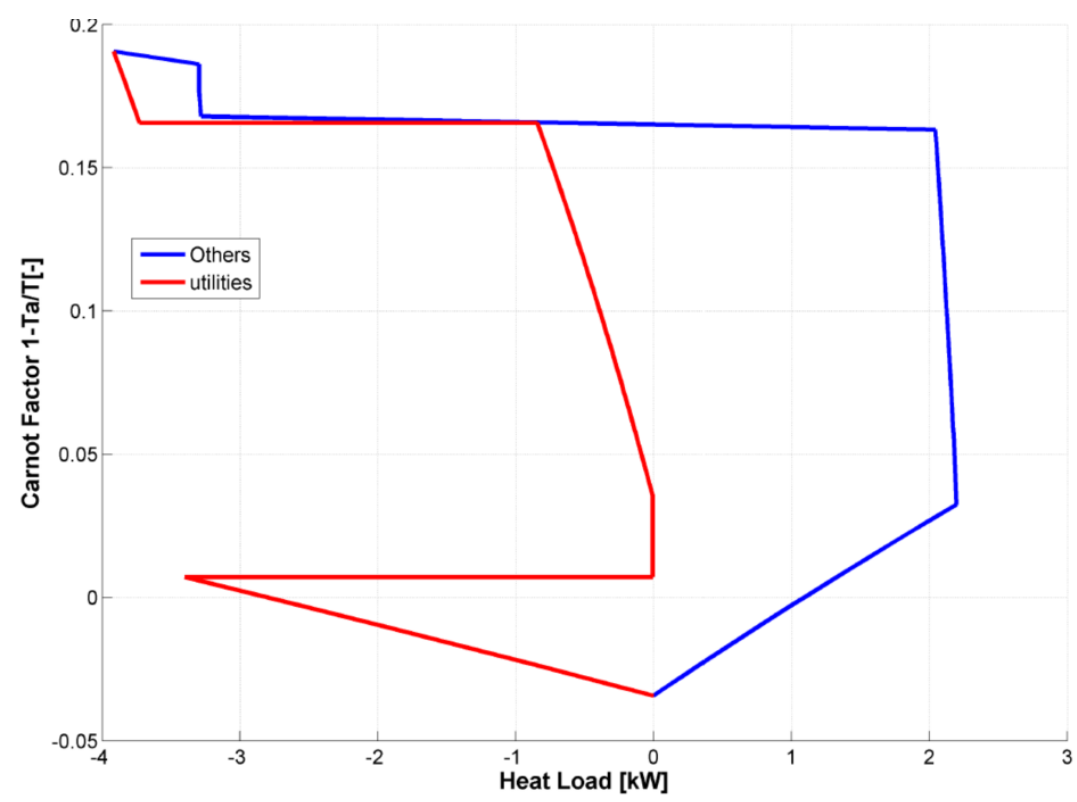

b)

Figure 9: ORC integration with Ammonia, a) point 1 and b) point 5

Table 7: ORC characteristics and outputs power for R1234yf and Ammonia

\begin{tabular}{ccccc}
\hline & \multicolumn{2}{c}{ Operating point 1 } & \multicolumn{2}{c}{ Operating point 5 } \\
\hline T condensation $\left[{ }^{\circ} \mathrm{C}\right]$ & R1234yf & Ammonia & R1234yf & Ammonia \\
T evaporation $\left[{ }^{\circ} \mathrm{C}\right]$ & 30 & 30 & 30 & 30 \\
T superheat $\left[{ }^{\circ} \mathrm{C}\right]$ & 81 & 81 & 82 & 82 \\
Flow rate $[\mathrm{kg} / \mathrm{s}]$ & 120 & 140 & 90 & 90 \\
$\dot{E}_{\text {pump }}[\mathrm{kW}]$ & 0.15 & 0.024 & 0.0227 & 0.0034 \\
$\dot{E}_{\text {turbine }}[\mathrm{kW}]$ & 0.2 & 0.1 & 0.031 & 0.0142 \\
$\eta_{\text {orc_cycle }}[\%]$ & 2.84 & 3.35 & 0.3455 & 0.3732 \\
$\dot{E}_{\text {shaft }}[\mathrm{kW}]$ shaft power & 8.04 & 9.8 & 8.05 & 9.18 \\
$\dot{E}_{\text {turbine }}[-]$ & 18.78 & 18.78 & 0.82 & 0.82 \\
$\dot{E}_{\text {shaft }}$ & & & 0.42 & 0.45 \\
\hline
\end{tabular}

For each point, the ORC is designed in order to satisfy the entire need of utility of the system and to close the energy integration of the processes (Figure 8 and Figure 9).

The integrated composite curve is obtained after integration of the composite curve and the minimum energy requirement from the external utility - the ORC. Figures 8 and 9 represent the variation of the Carnot factor as a function of the exchanged heat between the working fluid of the ORC mainly with the water circuit and the exhaust gases. The exergy losses are 
represented by the area between the composite curve and the utility curve. The optimization of the ORC loop consists in the minimization of this area.

The thermodynamic calculations are done with the open source code Coolprop, containing a library of 110 fluids and their thermo physical properties. The most accurate thermodynamic properties are obtained from the Helmholtz energy explicit type equation of state. The library and the property calculation method are explained in [28]. In the Helmholtz energy explicit formulation the total non dimensionalized energy $\alpha$ can be given as the sum of two contributions - the residual $\alpha \mathrm{r}$ and the ideal gas $\alpha 0: \alpha=\alpha \mathrm{r}+\alpha 0$ (7). The advantage of this formulation is that all other thermodynamic properties can be obtained through analytic derivatives of the terms $\alpha \mathrm{r}$ and $\alpha 0$. The Helmholtz free energy is a thermodynamic potential that measures the "useful" work obtainable from a closed thermodynamic system (at constant temperature).

The isentropic efficiency of the pump and the turbine are 0.8 and 0.7 respectively. The values of the isentropic efficiencies of the components are considered as average technology values and are applied for the calculations.

As the precise design of the ORC components is not defined for the moment, one can consider the values for the isentropic efficiency of the pump and the turbine from the literature - from 0.75 to 0.85 and from 0.7 to 0.9 [29]. One can observe the sensitivity of the ORC thermal efficiency (A.4) on these parameters (Figure A.4).

The isentropic efficiency of the turbine has an important impact on the ORC thermal efficiency. For example for point 1, with working fluid R1234yf from Table 7, isentropic efficiency variation of 0.1 can lead to around $1.5 \%$ variation of the ORC thermal efficiency in absolute value. The pump isentropic efficiency influence on the ORC thermal efficiency is much smaller. This can be explained by the differences in the values of the isentropic turbine work and the isentropic pump (or compressor) work. For the point 1 with working fluid $\mathrm{R} 1234 \mathrm{yf}$, these values are $2.84 \mathrm{~kW}$ and $0.16 \mathrm{~kW}$. Globally the ORC installation for vehicle purpose is characterized by relatively small working fluid flow. In addition, the vehicle is constrained from compactness and mass point of view. This induces the needs of small components size and impacts their efficiency.

\section{R1234yf}

For point 1, the superheating curve causes exergy losses because it is not following the curve of the exhaust gases. For operating point 5, the preheating stage is inducing losses due to the heat dissipated in the water circuit and the point 5 has a big self-sufficient zone. The ORC efficiency is $8 \%$ and table 9 indicates the characteristics of the cycle. The power on the turbine shaft represents between $15 \%$ and $42 \%$ of the engine output power.

\section{Ammonia}

The ammonia represents advantages to R1234yf in all operating points. This is due, because of the fluid characteristics, to the better following of the superheating curve. Also less exergy losses are generated in the preheating stage for the water circuit - near the self-sufficient zone for the cabin heating. Table 7 shows the comparison of the ORC characteristics for the working fluids. The ORC efficiency is $9 \%$, with $1 \%$ more than with R1234yf. The shaft power on the turbine is between $18 \%$ and $45 \%$, i.e. $3 \%$ more than with R1234yf.

The orders of magnitude of the simple ORC efficiency and the power on the turbine shaft lead to the conclusion that ORC presents an interest as a heat recovery technological option for a vehicle system. The first sensitivity analysis on the working fluid quantified the impact of the working fluid choice on the ORC efficiency. The choice of the working fluid has to be done taking into account the entire thermo economic and environmental criteria. 


\section{Summer case}

The ORC efficiency is lower for higher ambient temperatures because of the lower work produced by the turbine and due to diminished difference between the evaporation and the condensation level.

In the considered summer case with $30^{\circ} \mathrm{C}$ ambient temperature, the energy integration takes into account the engine and the cabin streams. The MER of the system for the summer is more important (Table 5) because the cabin air flow has to be cooled (Table 3 ). In the summer case no self-sufficient zone is observed (Figure A.1). The ORC efficiency for point 1 decreases to $6 \%$ instead of $8 \%$ for the winter case.

\subsubsection{Evaluation of the ORC for the winter case and ammonia fluid on the engine operating field}

The energy integration approach between the engine and the vehicle cabin is extended to the full diesel engine field and the performance indicators are represented (Figures 10 and 11):

- ORC net power in [kW], defined in equation (A.5).

- exergetic efficiency in [\%], defined in equation (A.6). The exergetic efficiency is the ratio between the net power-work delivered by the ORC and the exergy- heat received by the ORC system.

The diesel engine is evaluated on its total operating map.

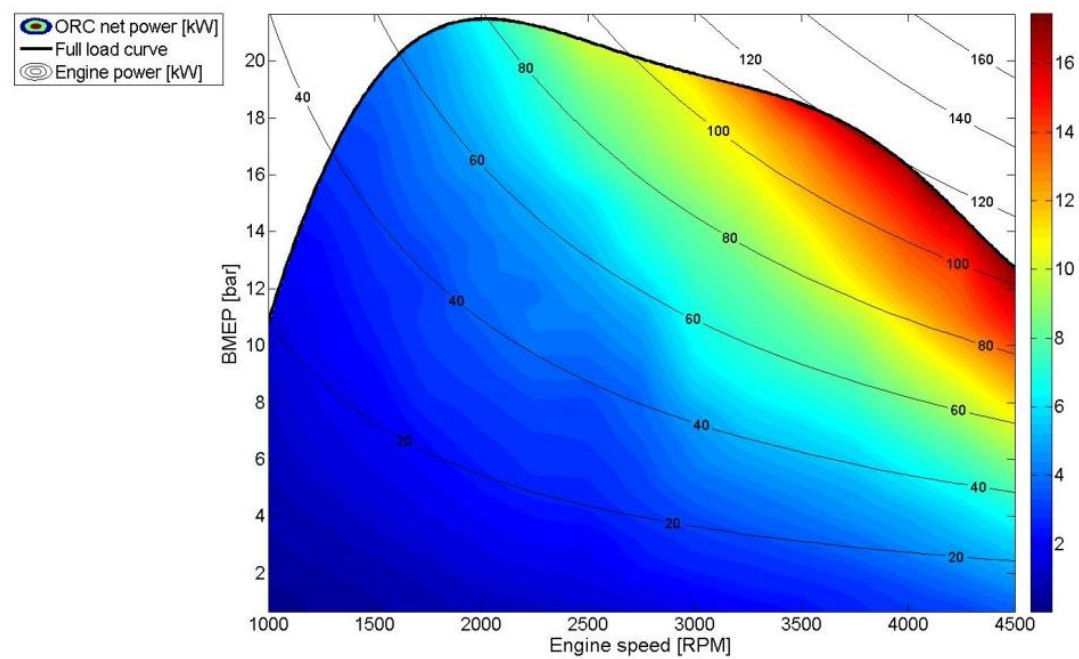

Figure 10: $\mathrm{ORC}$ net power on the diesel engine field, $\mathrm{T}_{\mathrm{ambient}}=0^{\circ} \mathrm{C}$

The hybrid electric powertrain operating points on NEDC (Table 1 and Figure B.3) are situated in the zones with low ORC net power output - between 1 and $5 \mathrm{~kW}$ maximum (Figure 10). This is an interesting indication for the sizing of the ORC components.

The representation of the ORC exergetic efficiency on the engine operating field illustrates the zones presenting maximal recovery potential. These zones correspond to the considered two hot sources - the water circuit and the exhaust gases. The water circuit's potential is situated in the low speed high load operating zone. The exhaust gases potential is situated in the high speed high loads zone. 


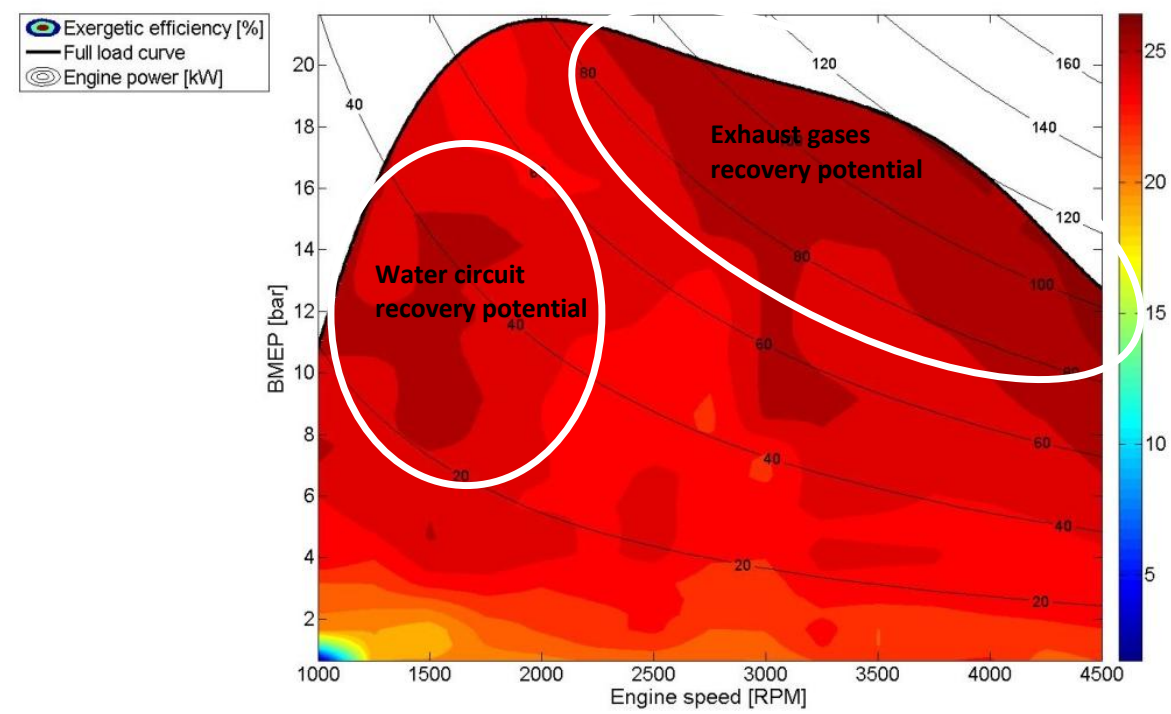

Figure 11: ORC exergetic efficiency on the diesel engine operating field, $\mathrm{T}_{\text {ambient }}=0^{\circ} \mathrm{C}$

This is interesting information for the adaptation on the ORC to the diesel engine in thermal or in hybrid electric powertrains.

In the case of pure thermal powertrain, the diesel engine provides the total power needed for the vehicle traction. This means that the engine is charged and the full operating field is used (Figure 12a). For the same size of the ICE, the potential of the ORC recovery is then more important for thermal powertrain than in a hybrid electric powertrain.

In the case of diesel engine integrated to a hybrid electric powertrain, the diesel engine provides partially the power for the traction. The operating zone is restricted to the low speeds and low loads zone (Figure 12b). Thus in a hybrid electric application one has interest to downsize the thermal engine to get a benefit effect of the energy recovery by placing the operating points of the diesel engine (in the hybrid electric powertrain) in the most charged zone.

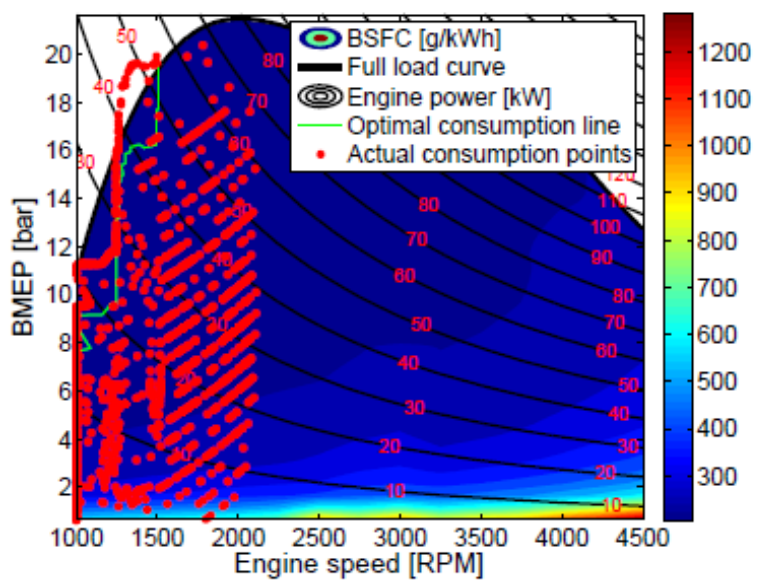

a)

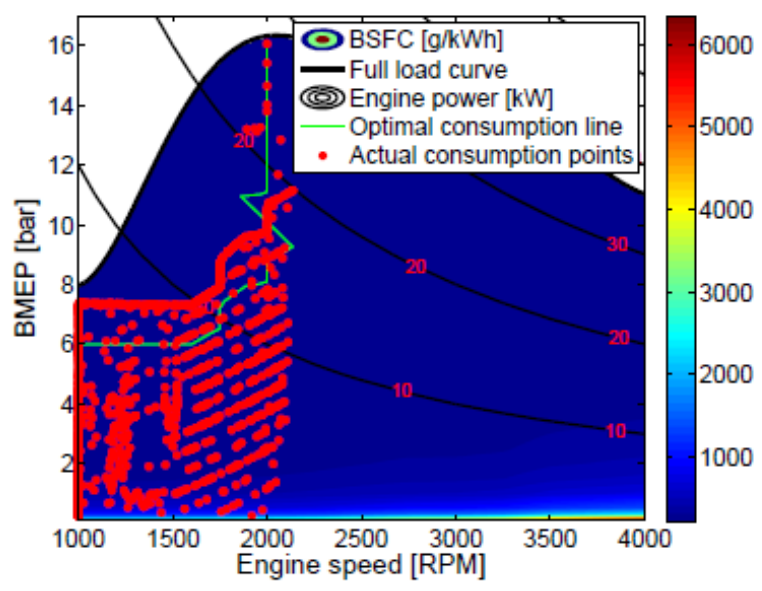

b)

Figure 12: NED Cycle operating points on engine fields, D class vehicle, a) thermal powertrain 2L ICE, b) hybrid electric powertrain $1.4 \mathrm{~L} \mathrm{ICE}$, Text $=0^{\circ} \mathrm{C}$

The ORC net output power is around maximum $5 \mathrm{~kW}$ in the use zones of the driving cycle (Figure 10). Figure illustrates the difference of the thermal engine usage and size in the case of thermal (a) and hybrid electric (b) propulsion. One can conclude that the $2 \mathrm{~L}$ is oversized 
for the needs of the hybrid electric propulsion. The potential of the waste heat recovery with ORC cycle is better in a hybrid electric powertrain with downsized thermal engine.

The optimal size of this downsized thermal engine will be determined by using a multiobjective optimization.

\subsection{Multi-objective optimization:}

The optimization methodology is applied for the design of an energy integrated system. The energy integration analysis shows that the thermal engine of $2 \mathrm{~L}$ is too powerful for a hybrid electric application (Figure 12b), because only small part of its nominal power is used during the NEDC and in combination with the hybrid electric powertrain. The objective is to use multi-objective optimization techniques to redefine the optimal design of a hybrid electric powertrain and the optimal ICE size, from efficiency and cost point of view. The simulation model represents a D-Class hybrid electric vehicle.

A two objective optimization is defined with the maximization of the powertrain efficiency and the minimization of the vehicle cost (8).

$$
\begin{aligned}
& \min \left(-\eta_{\text {powertrain }}(x), C_{\text {vehicle }}(x)\right), x \in X_{\text {decision_variables }}(8) \text {, with } \\
& \eta_{\text {powertrain }}=\operatorname{mean}\left(\frac{P_{\text {wheel }}}{P_{\text {fuel }}+P_{\text {elec }}}\right)[\%](9) \\
& C_{\text {vehicle }}=C_{\text {car_shell }}+C_{I C E}+C_{E M}+C_{S C}+C_{H V B T}[€](10)
\end{aligned}
$$

Equation 9 defines the Tank-to- Wheel powertrain efficiency and equation 10 defines the total vehicle cost. The vehicle cost model is defined and described in [23].

- electric motor cost in $€: 30 \frac{[€]}{\mathrm{kW}} * \mathrm{P}_{\text {elec }}[\mathrm{kW}](11)$

- thermal engine in $€: 15 \frac{[€]}{\mathrm{kW}} * \mathrm{P}_{\mathrm{ICE}}[\mathrm{kW}],(12)$

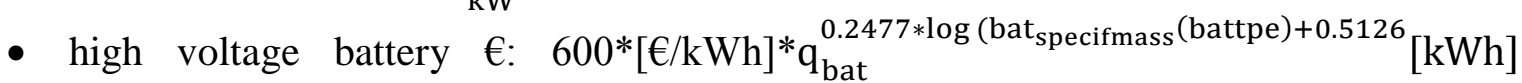
$q^{0.2477 * \log \left(\text { bat }_{\text {specifnass }}(\text { bat_type })+0.5126\right)}$ $q_{\text {bat }}$

qbat- battery capacity in $\mathrm{kWh}$

- super capacitor in $€: 15 \frac{[€]}{\mathrm{kW}} * \mathrm{P}_{\mathrm{sc}}[\mathrm{kW}]$, (14)

- $\quad$ car shell in $€: 17.3 *$ car $_{\text {shell }_{\text {mass[kg] }}}-3905.4(15)$

The decision variables are defined in Table 8:

Table 8: Decision variables for a multi-objective optimization

\begin{tabular}{ll}
\hline Decision variables & Range \\
\hline ICE displacement volume $[\mathrm{L}]$ & $0.8-1-1.4-1.6-2$ \\
EM power $[\mathrm{kW}]$ & $1-150$ \\
Battery energy $[\mathrm{kWh}]$ & $5-50$ \\
Number of supercapacitors $[-]$ & $1-10$
\end{tabular}

The OSMOSE superstructure (Figure 3) is launched and the solutions converged to the presented in Figure 13 Pareto frontier curve. The domain of defined solutions is between $25 \%$ and $45 \%$ efficiency of the powertrain, and $\mathrm{CO}_{2}$ emission from $140 \mathrm{~g} / \mathrm{km}$ to $30 \mathrm{~g} / \mathrm{km}$. The vehicle cost of the solutions varies between 30000 and $70000 €$. From Figure 13 one can see 
that the $\mathrm{CO}_{2}$ emissions decrease with the increasing of the powertrain efficiency. This is due to the increased part of the electric powertrain. The increasing of the electric part of the powertrain increases the hybridation ratio. The important size of the electric components of the powertrain (battery and electric machine) leads to increase of the vehicle cost. For example the solution with $30 \mathrm{~g} \mathrm{CO}_{2} / \mathrm{km}$ has the highest powertrain efficiency of $45 \%$ and the important cost of $70000 €$ (point in red).

The $\mathrm{CO}_{2}$ emissions are between $140 \mathrm{~g} \mathrm{CO}_{2} / \mathrm{km}$ and $30 \mathrm{~g} \mathrm{CO}_{2} / \mathrm{km}$, which is corresponding to very low fuel consumption close to $1 \mathrm{~L} / 100 \mathrm{~km}$ (Figure 13).

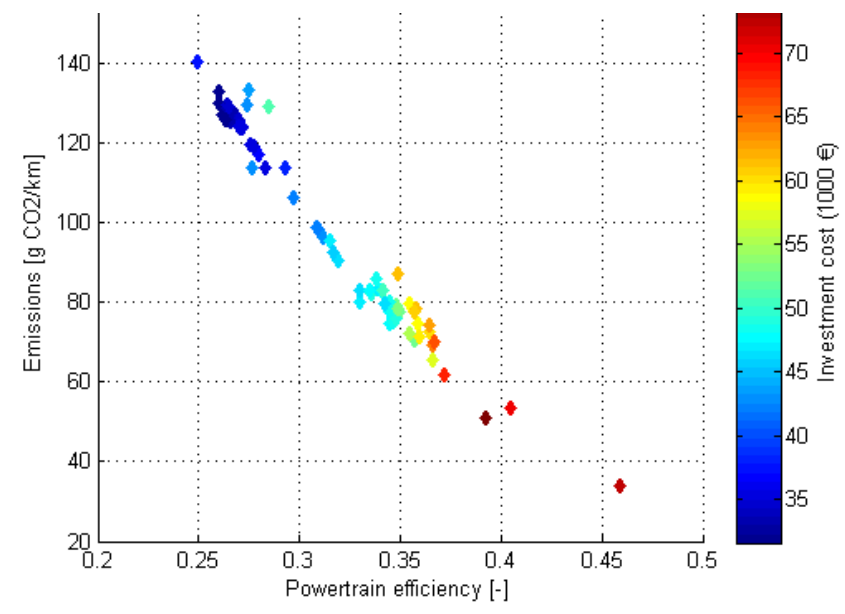

a)

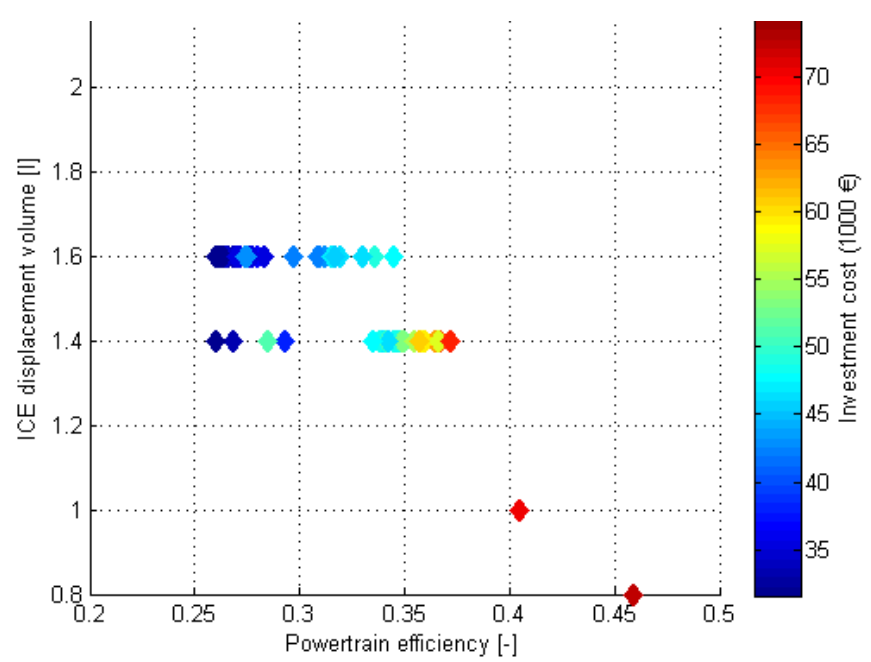

b)

Figure 13: Results from the multi-objective optimization and Pareto Frontier Curves, color bar in thousands of Euros, a) $\mathrm{CO} 2$ emissions vs powertrain efficiency, b) ICE displacement vs powertrain efficiency

Figure $13 \mathrm{~b}$ shows that most of the optimal techno-economic solutions converge on optimal displacement volume of $1.4 \mathrm{~L}$ and 1.61 diesel engines for the hybrid electric powertrain and a D-class vehicle.

An optimal definition of the studied D-Class vehicle is detailed in the following (Table 8): Table 8: D-class hybrid electric vehicle, with hybrid electric powertrain

\begin{tabular}{lr}
\hline Vehicle definition & Value \\
\hline ICE displacement volume $[\mathrm{L}]$ & 1.4
\end{tabular}




\section{Conclusion:}

This paper introduces the notion of a vehicle integrated energy system and studies the application of process integration techniques on an autonomous and dynamic system - the vehicle. The energy balance of the thermal engine is discussed. The energy requirement related to the vehicle comfort service is assessed depending on the seasonal temperature. This is done through a winter and summer study case process analysis for the extended vehicle energy system. The energy integration was studied for adapted dynamic profile, represented by characteristic operating points, in the case of a hybrid electric vehicle. The mobility and comfort energy requirements are integrated.

During the NEDC, the vehicle is used in zones with dominant heat dissipation in the engine water circuit rather than in the exhaust heat dissipation. The integration of simple ORC is done in these conditions in order to estimate the very first potential of ORC in a hybrid electric vehicle application.

Indeed a high power ratio between $18 \%-45 \%$ is obtained in function of the operating point and the working fluid. That shows that ORC can be a viable option for cold utility required by the system. The highest obtained ORC efficiency is $9 \%$ with Ammonia as a working fluid.

As key results coming out from the applied methodology, one can consider that the vehicle is a system with excess of heat and for the energy integration, a cold utility is required. The winter case requires less cold utility because of the self-sufficient zone, insured by the heat requirement of the cabin by the engine water circuit. For the most loaded operating point (point 1), the required MER is between of $33 \mathrm{~kW}$ to $36 \mathrm{~kW}$ depending on the cabin comfort demand. The engine cooling circuit is important for waste heat recovery. At low speed and low load engine operating points where the powertrain is used on NEDC, the heat load in the water circuit is ever greater than that in the exhaust gases. The oil circuit load is relatively small due the oil temperature and flow regulation. The ambient temperature influences strongly the efficiency of the studied utility for waste heat recovery - the ORC.

The energy integration approach between the engine and the vehicle cabin is extended to the full diesel engine operating field. The net power output potential is evaluated which helps to obtain an indications about the size of the ORC installation.

An optimal techno-economic design with adapted size of the powertrain equipment is proposed for a hybrid electric powertrain, with an engine downsizing from $2 \mathrm{~L}$ to $1.4 \mathrm{~L}$. The total cost of the hybrid electric D-class vehicle for the customer is estimated to $44,000 €$. 


\section{Acknowledgments}

The authors highly appreciate the financial support of the PSA R\&D division.

\section{Appendix 1:}

$$
\begin{aligned}
& \dot{E}_{t}=\dot{m}^{*}\left(h_{3}-h_{4}\right) * \text { isentropic_eta_turbine } \\
& \dot{E}_{p}=\dot{m}^{*}\left(h_{2}-h_{1}\right) / \text { isentropic_eta_pump } \\
& \dot{Q}_{i n}=M E R \quad \text { (A.3) } \\
& \eta_{\text {orc_cycle }}=\frac{\dot{E}_{t}-\dot{E}_{p}}{Q_{i n}} \quad \text { (A.4) } \\
& \dot{P}_{\text {net }}=\dot{E}_{\text {net }}=\left|\dot{E}_{\text {turbine }}\right|-\left|\dot{E}_{\text {pump }}\right| \\
& \zeta=\frac{\dot{P}_{\text {net }}}{\dot{E}_{\text {exhaust_gas }}+\dot{E}_{\text {cooling_water }}} \text { (A.5) }
\end{aligned}
$$

\begin{tabular}{cc}
\multicolumn{2}{c}{ Table A.1 : Fluids heat capacities } \\
\hline Fluid & Heat capacity $\left[\mathbf{J} / \mathbf{k g}^{*} \mathbf{k}\right]$ \\
\hline Air & 1005 \\
Water & 4200 \\
Oil & 2200 \\
Exhaust gases & 1100 \\
\hline
\end{tabular}
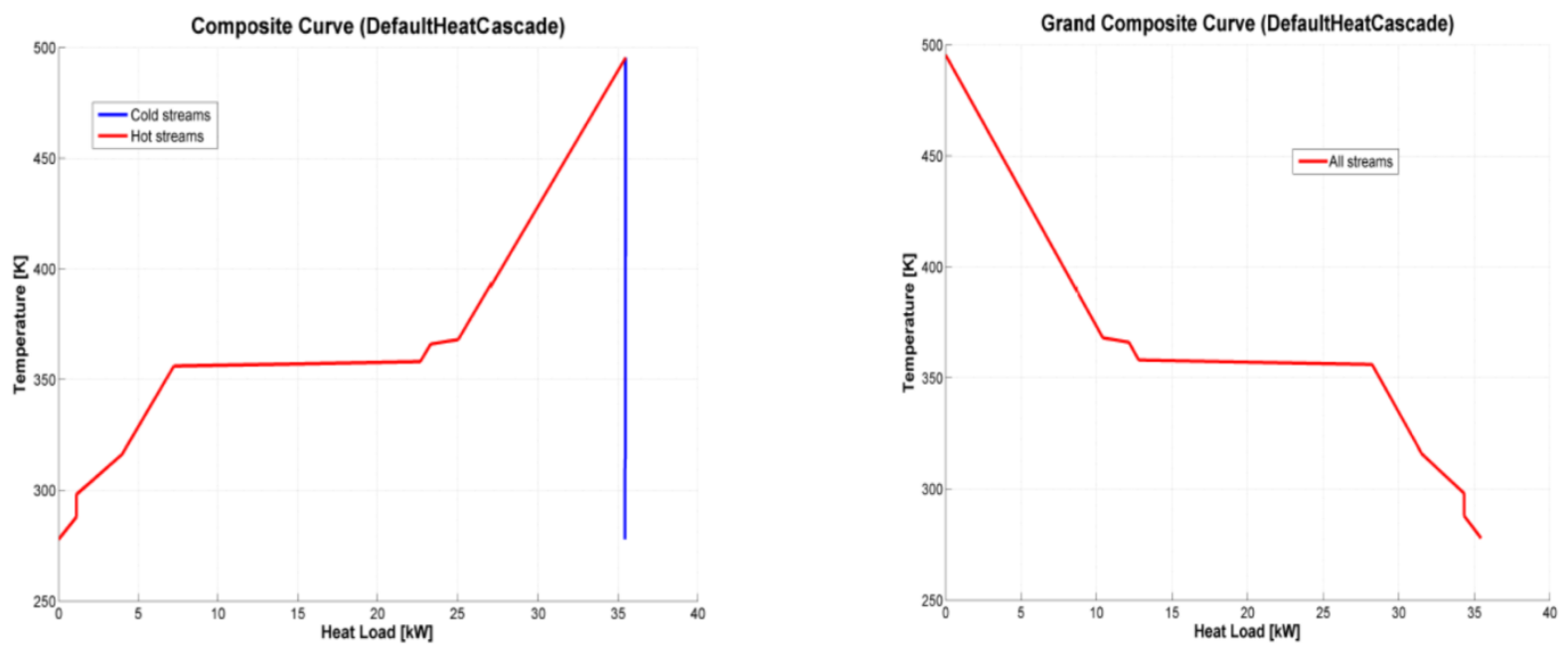

Figure A.1: Composite Curves and Grand Composite Curve for operating point 1, in summer

\section{Grand Composite Curve (GCC)}

Figure A.2 presents GCC corresponding to the streams of the studied in [19] energy system. The following observations are of interest: 
1. The Pinch Point divides the diagram in two regions, above and below the Pinch, in which the heat recovery problem can be analysed separately.

2. Above the Pinch, there is a need only for hot utilities. Below the Pinch, only cold utilities must be used.

3. The 'pockets' of the GCC designate possible heat recovery by process-process exchange.

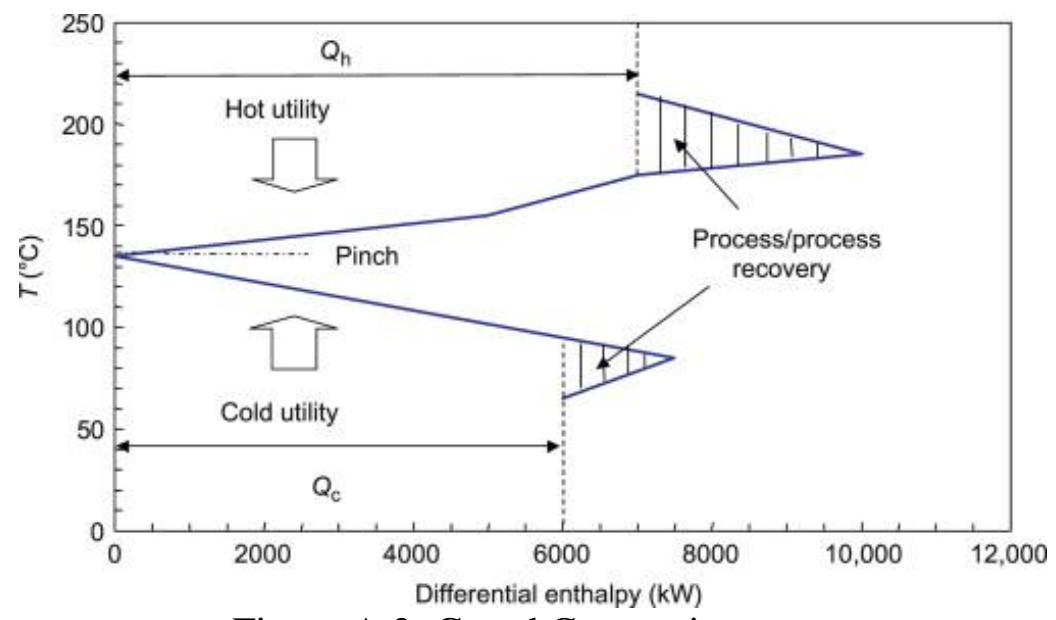

Figure A.2: Grand Composite curve
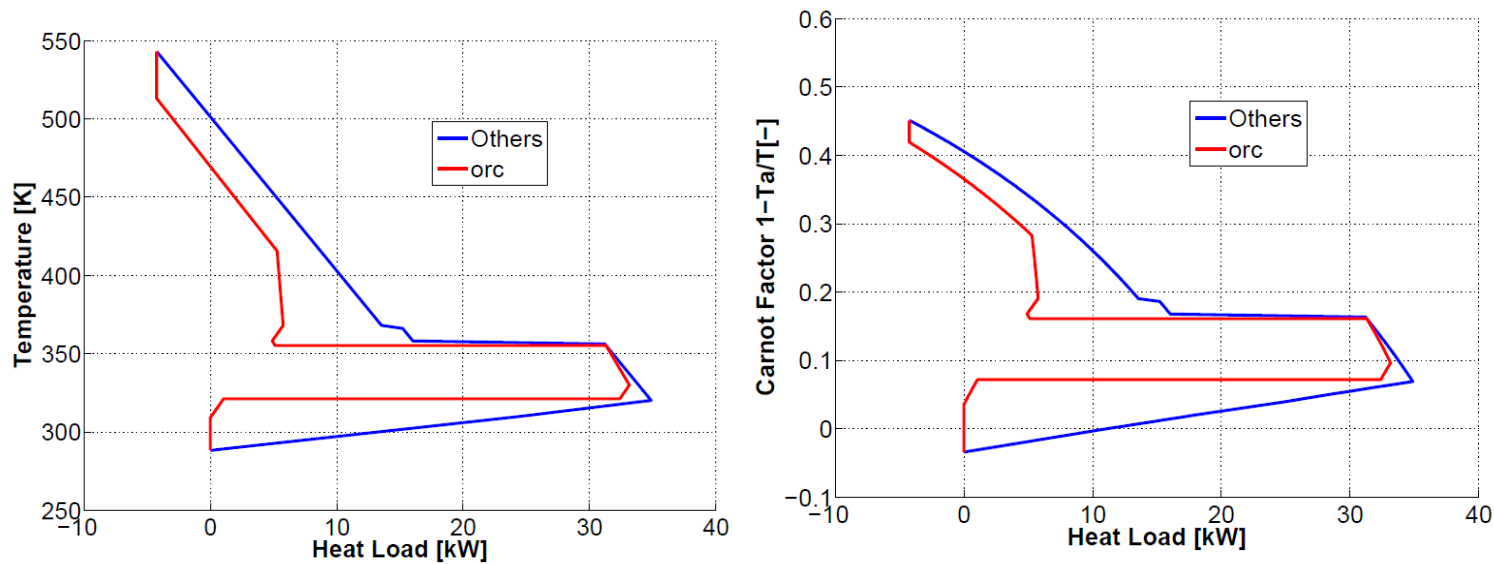

Figure A.3 : Representation in the axes T- Q and Carnot Factor - Q for point 1 

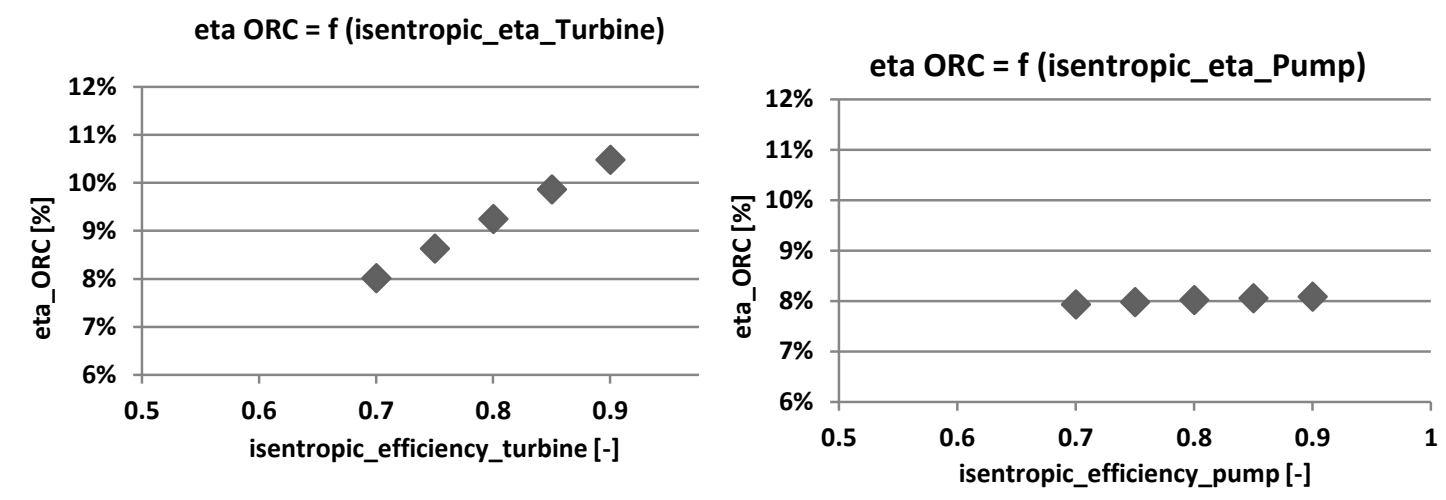

Figure A.4: Sensitivity of the ORC efficiency on the pump and turbine isentropic efficiency

Variation for point 1, working fluid R1234yf, from Table 7

\section{Appendix 2:}

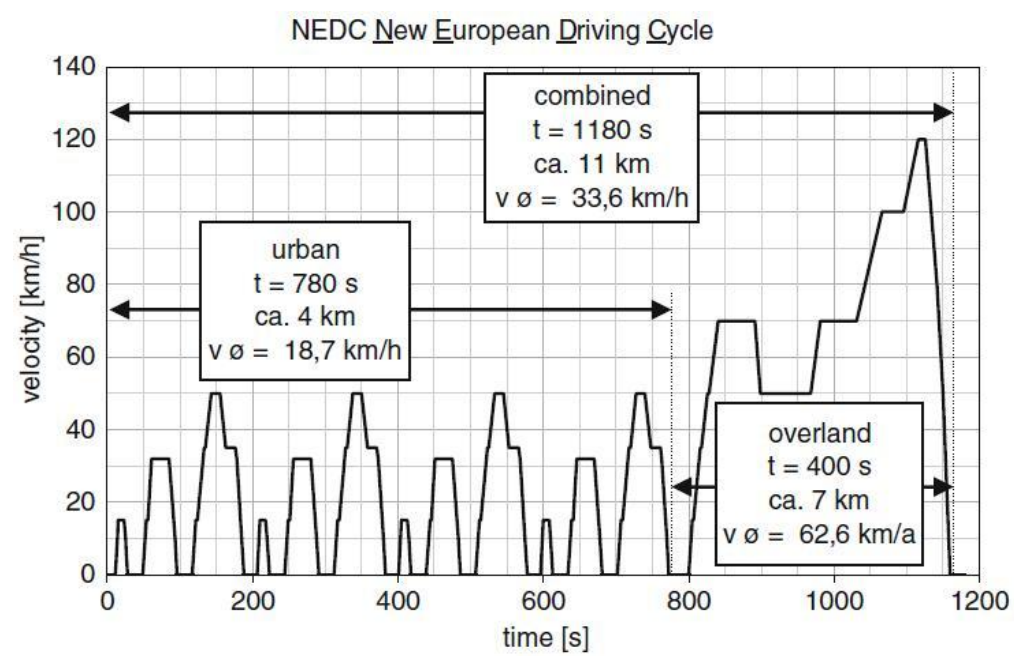

Figure B.1: NEDC characteristics

Typical operating clusters (periods): The centroid cluster algorithm k-means is described in [30]. According to the literature, the hierarchical and partitional algorithm approaches can be found for data analysis. In this article k-means proportional algorithm is used to define the typical power demand periods. K-means is greedy optimization algorithm, the goal of which is to minimize the squared error overall $N_{K}$ clusters (1). 

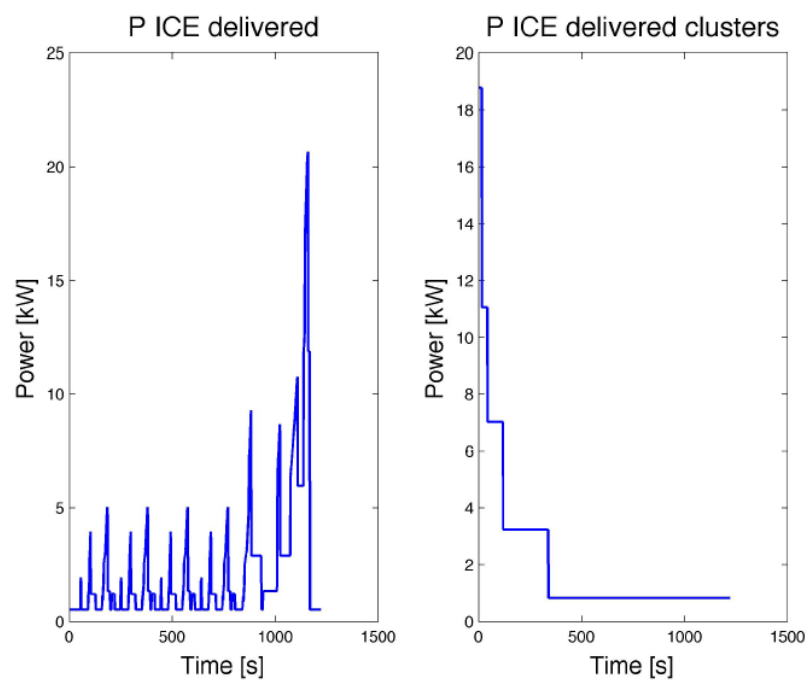

Figure B.2: Clustering of the thermal engine delivered power for middle class hybrid electric vehicle, on NEDC Cycle

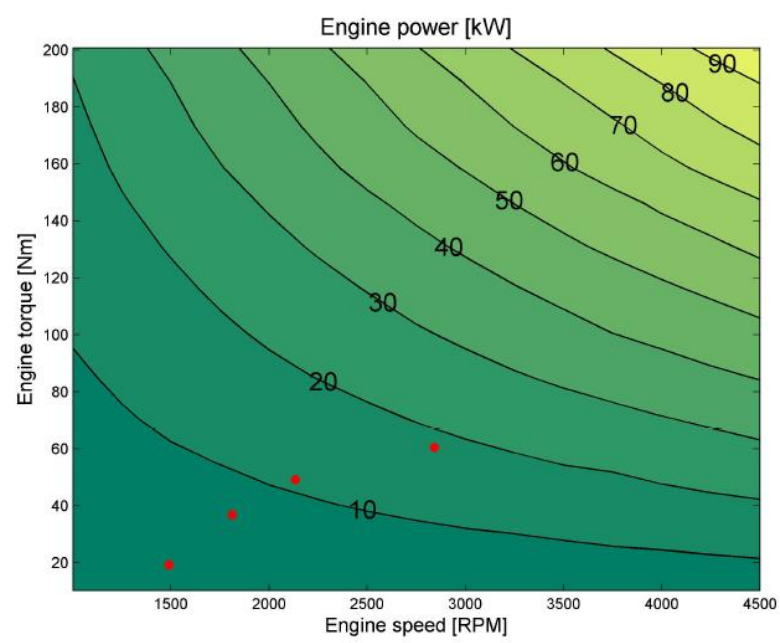

Figure B.3: Position of the thermal engine power clusters on the diesel engine operating field

\section{References}

[1] J.A. Caton, The thermodynamic characteristics of high efficiency, internal-combustion engines, Energy Conversion and Management, Volume 58, June 2012, Pages 84-93

[2] U. Spicher - Analysis of the efficiency of future powertrains for individual mobility, MTZ 02/2012, volume 73, Germany

[3] J.P. Liu, J.Q. Fu, C.Q. Ren, L.J. Wang, Z.X. Xu, B.L. Deng, Comparison and analysis of engine exhaust gas energy recovery potential through various bottom cycles, Applied Thermal Engineering, 50, (2013), 1219-1234

[4] S. Bari, S. N. Hossain, Waste heat recovery from a diesel engine using shell and tube heat exchanger, Applied Thermal Engineering, 61, (2013), 355-363

[5] Ch. Sprouse III, Ch. Depcik, Review of organic Rankine cycles for internal combustion engine exhaust waste heat recovery, Applied Thermal Engineering, 51, (2013), 711-722

[6] D. Jung, S. Park, K. Min, Selection of appropriate working fluids for Rankine cycles used for recovery of heat from exhaust gases of ICE in heavy-duty series hybrid electric vehicles, $\begin{array}{lllll}\text { Applied Thermal } \quad \text { Engineering, 338-345, } & \text { (2015), }\end{array}$ dx.doi.org/10.1016/j.applthermaleng.2015.02.002. 
[7] A. Boretti, Recovery of exhaust and coolant heat with R245fa organic Rankine cycles in a hybrid passenger car with a naturally aspirated gasoline engine, Applied Thermal Engineering, 36, (2012), 73-77

[8] S.Quoilin, S. Declaye, B. F. Tchanche, V. Lemort, Thermo-economic optimization of waste heat recovery Organic Rankine Cycles, Applied Thermal Engineering, 31, (2011), 2885-2893

[9] E.H. Wang, H.G. Zhang, B.Y. Fan, M.G. Ouyang, F.Y. Yang, K. Yang, Z. Wang, J. Zhang, F.B. Yang, Parametric analysis of a dual-loop ORC system for waste heat recovery of a diesel engine, Applied Thermal Engineering, 67, (2014), 168-178

[10] Y. Zhu, L. Jiang, V. Jin, L. Yu, Impact of built-in and actual expansion ratio difference of expander on ORC system performance, Applied Thermal Engineering, 71, (2014), 548-558

[11] V. Dolz, R. Novella, A. García, J. Sánchez.- HD Diesel engine equipped with a bottoming Rankine cycle as a waste heat recovery system. Part 1: Study and analysis of the waste heat energy. Applied Thermal Engineering 2012; 36:269-278.

[12] R. Capata, C. Toro, Feasibility analysis of a small-scale ORC energy recovery system for vehicular application, Energy Conversion and Management, Volume 86, October 2014, Pages 1078-1090

[13] B. Peris, J. Navarro-Esbrí, F. Molés,- Bottoming organic Rankine cycle configurations to increase Internal Combustion Engines power output from cooling water waste heat recovery, Applied Thermal Engineering Volume 61, Issue 2, 3 November 2013, Pages 364-371

[14] H. Choa - Performance characteristics of an automobile air conditioning system with internal heat exchanger using refrigerant R1234yf, Applied Thermal Engineering Volume 61, Issue 2, 3 November 2013, Pages 563-569

[15] P. Bombarda, C.M. Invernizzi, C. Pietra- Heat recovery from Diesel engines: A thermodynamic comparison between Kalina and ORC cycles. Applied Thermal Engineering 2010; 30:212-219.

[16] J. J. Klemeš, Process Integration (PI): An Introduction, In Woodhead Publishing Series in Energy, edited by Jiří J. Klemeš, Woodhead Publishing, 2013, Pages 3-27, Handbook of Process Integration (PI), ISBN 9780857095930 , http://dx.doi.org/10.1533/9780857097255.1.3.

[17] Linnhoff B., Hindmarsh E., 1983, The pinch design method for heat exchanger networks, Chemical Engineering Science, 38, 745-763.

[18] Petar Sabev Varbanov, 2 - Basic Process Integration Terminology, In Woodhead Publishing Series in Energy, edited by Jiří J. Klemeš, Woodhead Publishing, 2013, Pages 2878, Handbook of Process Integration (PI), ISBN 9780857095930, http://dx.doi.org/10.1533/9780857097255.1.28.

[19] A. C. Dimian, C. S. Bildea, A. A. Kiss, Chapter 13 - Pinch Point Analysis, In: Alexandre C. Dimian, Costin S. Bildea and Anton A. Kiss, Editor(s), Computer Aided Chemical Engineering, 35, 2014, 525-564

[20] M. Bendig, F. Maréchal, D. Favrat,- Defining "Waste Heat" for industrial processes Applied Thermal Engineering Volume 61, Issue 1, 15 October 2013, Pages 134-142 [21]M. Khennich and N. Galanis, Optimal design of ORC systems with a low temperature heat source. Entropy, 14(2):370-389, 2012.

[22] Z. Dimitrova, F. Maréchal, Environomic design of vehicle integrated energy systemsapplication on a hybrid electric vehicle energy system, CET, volume 39, 2014, p. 475-480, DOI: $10.3303 / C E T 1439080$

[23] Z. Dimitrova, F. Maréchal, Environomic design of vehicle energy systems for optimal mobility service, Energy (2014), http://dx.doi.org/10.1016/j.energy.2014.09.019 
[24] S. Fazlollahi, F. Maréchal, Multi-objective, multi-period optimization of biomass conversion technologies using evolutionary algorithms and mixed integer linear programming (MILP), Applied thermal engineering, 50 (2013) 1504- 1513

[25] F. Marechal, B. Kalitventzeff, Utilities integration (energy, water), in: L. Puigianer, G. Heyen (Eds.), Computer Aided Process and Product Engineering, vol. 1, Wiley-VCH, Weinheim, Germany, 2006, pp. 327-381

[26] F. Maréchal, Pinch Analysis, UNESCO Encyclopedia of Life Support Systems, EOLSS Publishers Co Ltd., Oxford, UK, 2008. (Chapter 3.19.1.7).

[27]L. Borel, D. Favrat, Thermodynamique et Energetique, Presses polytechniques et universitaires romandes, Lausanne, 2011, (Chapter 10.2.7)

[28]I. H. Bell, J. Wronski, S. Quoilin, V. Lemort, Pure and pseudo-pure fluid thermophysical property evaluation and the open source thermophysical property library Coolprop, 2014, Industrial and Engineering chemistry research, volume 53, pages: 2498-2508.

[29] Y.A. Cengel and M.A. Boles - Thermodynamics an Engineering Approach, yjresources.files.wordpress.com/2009/05/4-first-law-control-volume-isentropic-

efficiency.pdf, accessed on 03/09/2014

[30] S. Fazlollahi and all, Milti-objective, multi-period optimization of district energy systems 1- Selection of typical operating periods, Computers and Chemical Engineering, 65, (2014), 54-66 